\title{
el plan del Delta holanda
}

Holanda carece de recursos naturales de superficie, por lo que su desarrollo se ha orientado hacia la industrialización y máximo euidado del suelo para la explotación agrícola. La parte occidental del mismo se halla a más bajo nivel que el mar, y en ella habita el 65 por 100 de su población.

En su origen, la costa presentaba un carácter recortado de islas, ensenadas y promontorios que la mano del hombre transformó, primero, en lagos (polders), y después, en tierras fértiles. Estas obras marítimas protegen las tierras áridas por medio de diques que exigen esmerada conservación, y aún así, no son raras las vio. lentas inundaciones.

Uno de los grandes problemas que esta situa. cíón crea lo constituye el complejo abastecimiento de aguas, vías de comunicación y desagüe de los ríos hacia el mar en la zona del Delta, es decir, del suroeste del país para la protección de la cual se ha constituido una Comisión nacional.

Después de serios estudios se llegó a la conclusión que la mejor defensa de los embates del mar es la de cerrar los brazos del mismo que se internan en el continente. El complejo de obras hidráulicas constituye el plan de mejoras y defensas para cuyo desarrollo y ejecución se ha previsto un periodo de veinticinco años.

El proyecto general es muy ambicioso y com. prende obras, no sólo marítimas, sino viales estructurales, en las que las obras de fábrica son variadas y de distinta naturaleza. En este trabajo se describen, a grandes rasgos, los te-

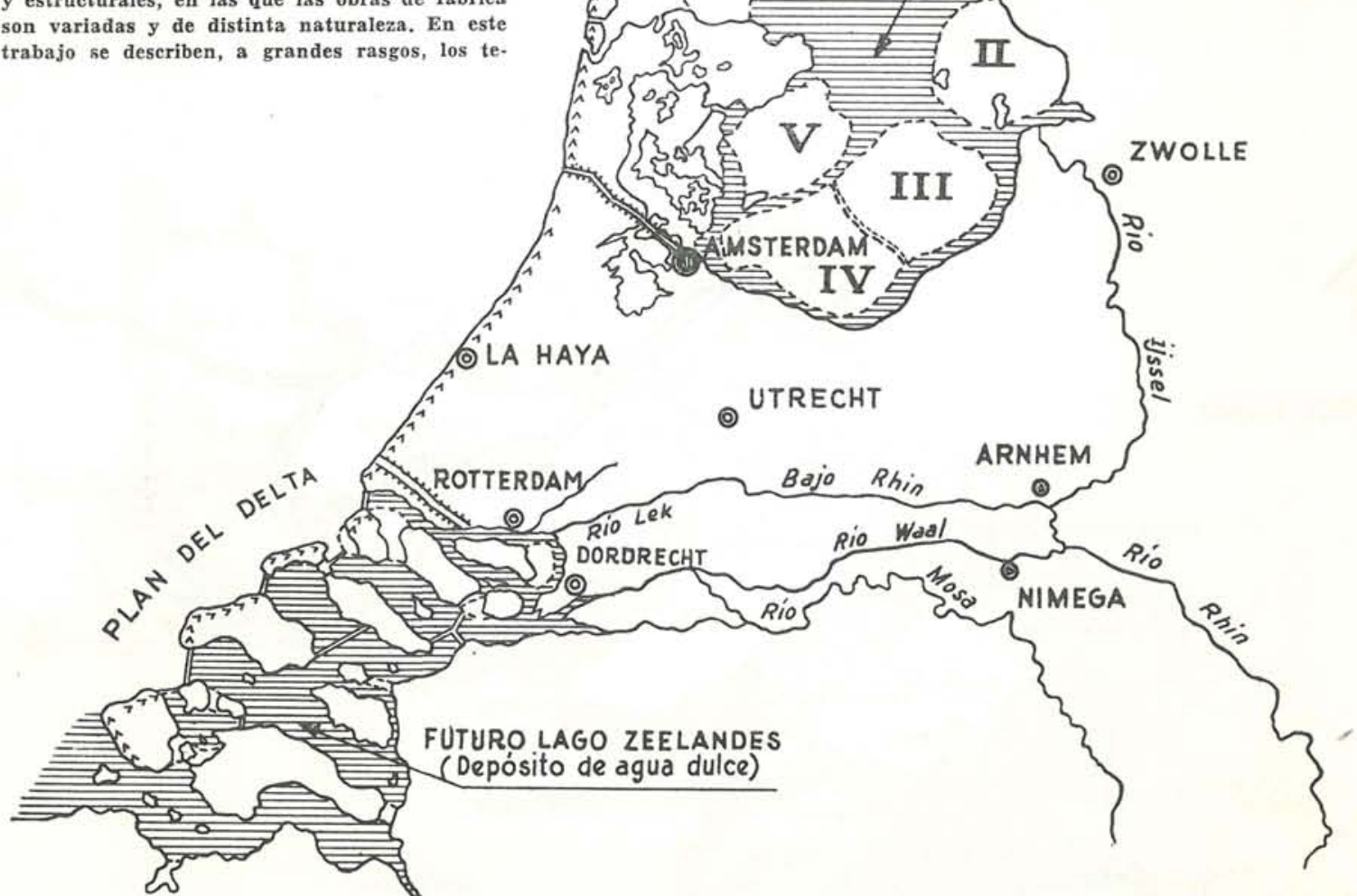

^^^^^^ Dunas y diques de contención

- Costas del territorio en el siglo XIII

....- Costas sucesivas al anexionar tierras a lo largo de los siglos

- Grandes diques de ciecre (construidos ó en proyecto)

num Nuevos canales de salida de los puertos de Amsterdam y Rotterdem.

\section{POLDERS ANEXIONADOS AL CERRAR EL ZUIDERZEE}

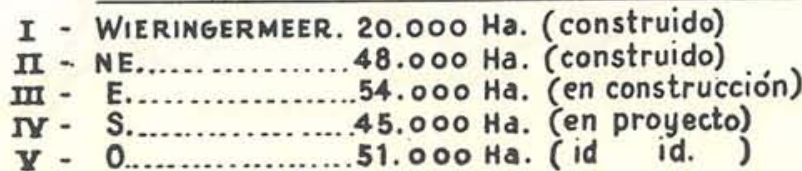


mas principales objeto de los 11 apartados en que se ha subdividido el proyecto general de ejecución y, además, se complementan las descripciones con datos adicionales referentes a las obras ya empezadas y los métodos construetivos en ellas empleados. De estas últimas obras merece especial atención el puente Nabla, situado en el Delta: es de hormigón pretensado, y cuenta con 17 tramos de 60 m de luz cada uno. Esta enorme estructura, además de su extensa longitud y servir de apoyo a una calzada de $22,80 \mathrm{~m}$ de anchura, se halla sometida a los tre. mendos empujes que $1 \mathrm{~s}$ aguas del mar ejercen, por un lado, y por el otro, las aguas dulces del brazo Haringvliet, estuario común de los ríos Rin y Mosa, ya que el puente sirve de soporte para las compuertas que han de regular los caudales de agua dulce y cerrar el paso al agua del mar. Las pilas que soportan el tablero con interposición de articulaciones de caucho, son las encargadas de transmitir los empujes de aguas al terreno.

El pretensado está constituido por 193 cables, de trazado parabólico, trenzados con 51 alambres de $6 \mathrm{~mm}$ de diámetro cada uno, que se hallan sometidos a un esfuerzo de 136,8 t. El pretensado transversal se ha realizado con cables tipo Freyssinet de 12 alambres, de 7 mm de diámetro, trabajando a $43,2 \mathrm{t}$ por cable $\mathrm{y}$ de trazado rectilineo.

Las vigas del tablero son del tipo prefabricado, con lo que se han conseguido notorias ventajas. Se tuvo muy en cuenta la corrosión para el estudio de cables.

En el cáleulo resistente de las vígas fue objeto de consideración la teoría en piezas prismáticas y su posible validez en este caso particular. Para mayor seguridad se preparó un modelo reducido. Los resultados obtenidos en los ensayos mostraron que, tanto con la teoría de piezas prismáticas como admitiendo la estructura como placa plegada, el análisis teórico no difirió más del 10 por 100 de los resultados experimentales. El segundo problema consistió en la posibilidad de aplicar la teoría de transmisión de empujes o de reacciones en las zonas de fuerzas con. centradas, en las que las teorías de viga o placa de diferencia relativa resultaba de consideración.

Para el caso de rotura se estudiaron distintas soluciones referentes a las superficies de contacto $y$ extremidades de las vigas. Los ensayos sobre modelo sirvieron de complemento a las previsiones que en los distintos análisis de estas zonas y superficies se habian realizado.

Fue también objeto de estudio la influencia diferencial de la temperatura, con el sol incidiendo de un lado y sombra en el otro.

Finalmente, se preparó un modelo reducido del conjunto de la obra, apreciándose discrepancias pequeñas y admisibles con relación a las pre. visiones analiticas.

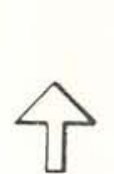

MAR DEL NORTE

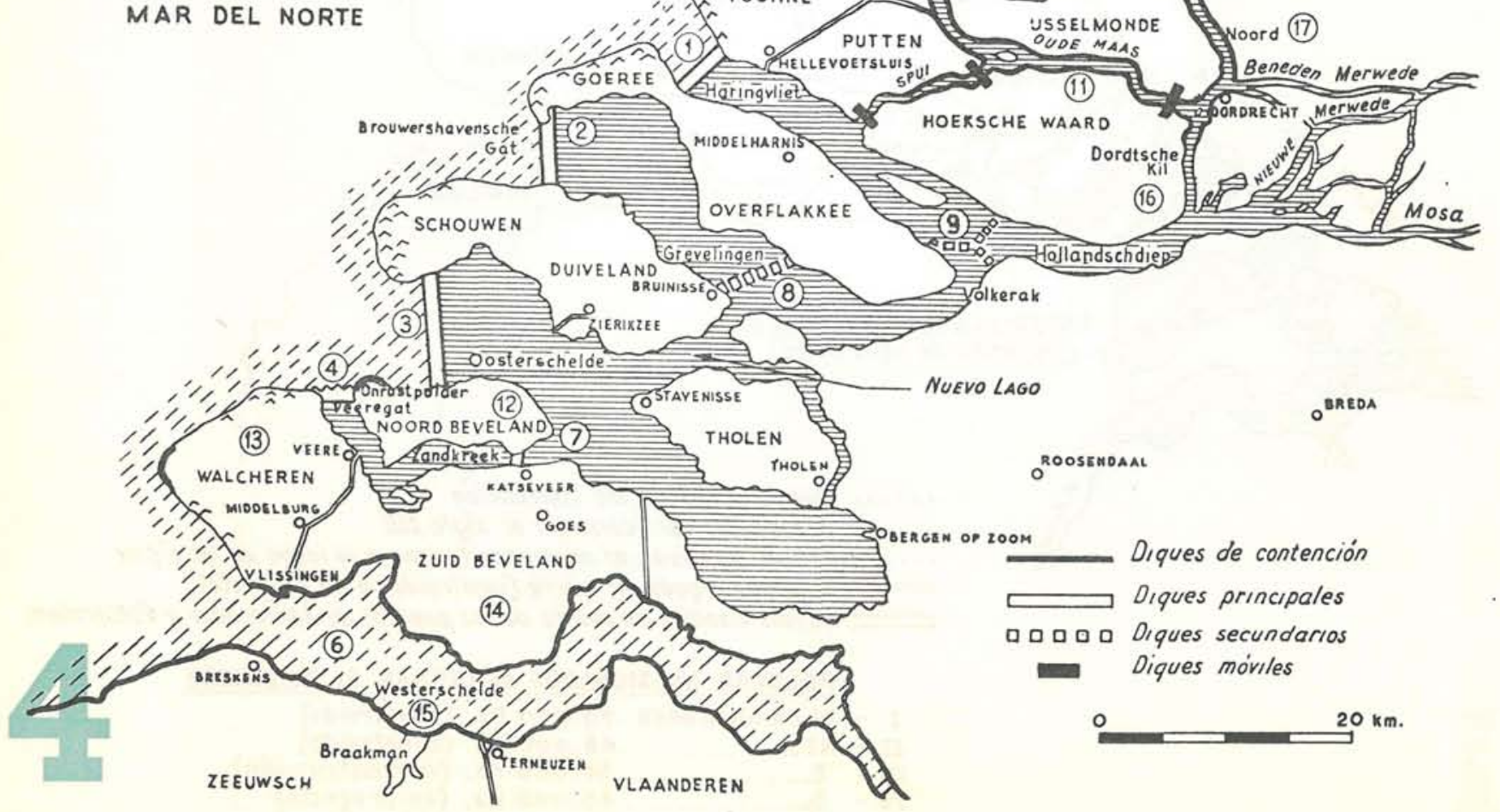




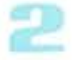

Periodo intensivo de la construccíón del dique de cierre. Obsérvese la fortísima corriente de agua

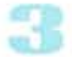

Vista del dique de cierre terminado, cuya longitud sobrepasa los 30 kilóme tros. brecha aún libre.
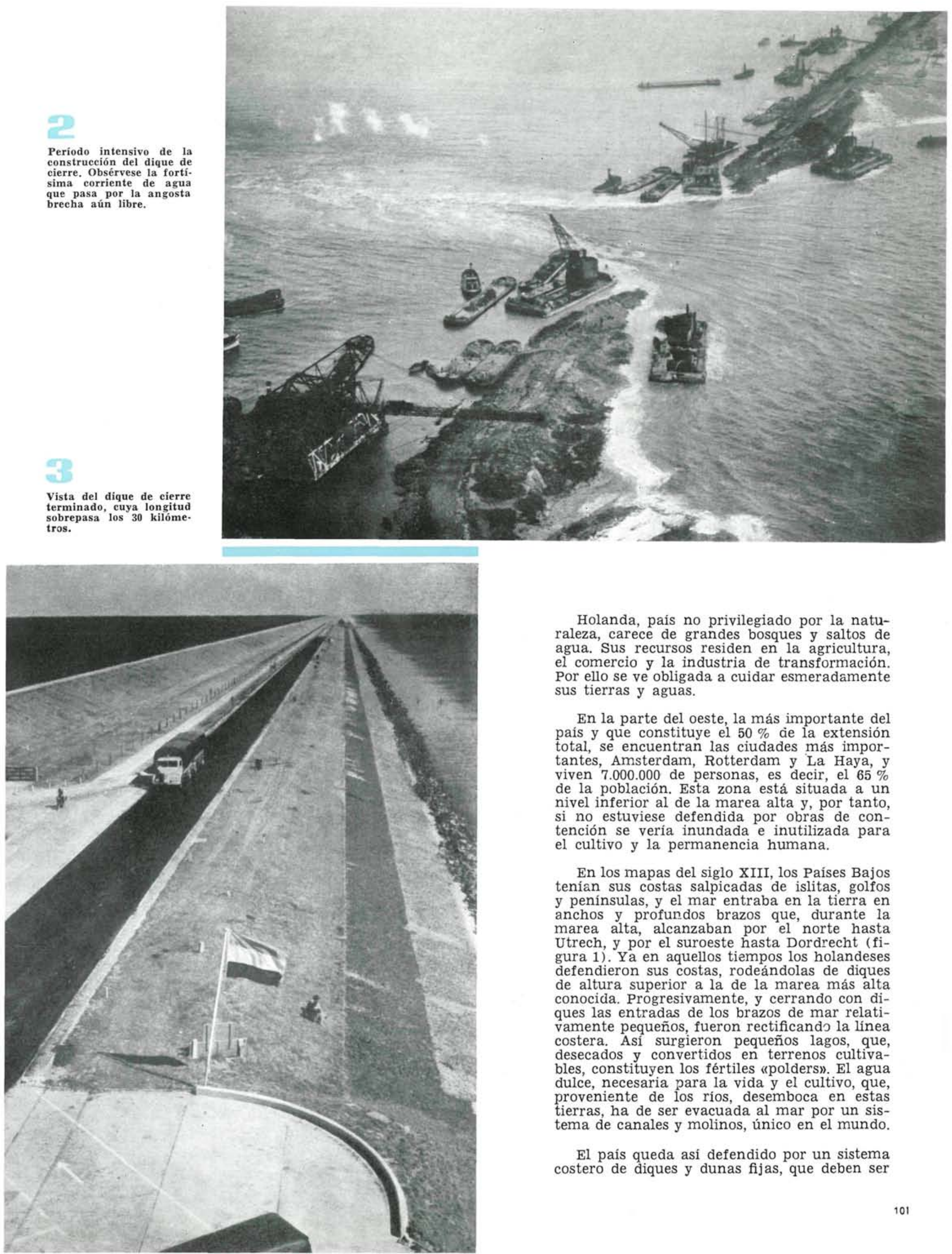

Holanda, país no privilegiado por la naturaleza, carece de grandes bosques y saltos de agua. Sus recursos residen en la agricultura, el comercio y la industria de transformación. Por ello se ve obligada a cuidar esmeradamente sus tierras y aguas.

En la parte del oeste, la más importante del país y que constituye el $50 \%$ de la extensión total, se encuentran las ciudades más importantes, Amsterdam, Rotterdam y La Haya, y viven 7.000 .000 de personas, es decir, el $65 \%$ de la población. Esta zona está situada a un nivel inferior al de la marea alta $\mathrm{y}$, por tanto, si no estuviese defendida por obras de contención se vería inundada e inutilizada para el cultivo y la permanencia humana.

En los mapas del siglo XIII, los Países Bajos tenian sus costas salpicadas de islitas, golfos y penínsulas, y el mar entraba en la tierra en anchos y profundos brazos que, durante la marea alta, alcanzaban por el norte hasta Utrech, y por el suroeste hasta Dordrecht (figura 1). Ya en aquellos tiempos los holandeses defendieron sus costas, rodeándolas de diques de altura superior a la de la marea más alta conocida. Progresivamente, y cerrando con diques las entradas de los brazos de mar relativamente pequeños, fueron rectificando la línea costera. Así surgieron pequeños lagos, que, desecados y convertidos en terrenos cultivables, constituyen los fértiles "polders». El agua dulce, necesaria para la vida y el cultivo, que, proveniente de los ríos, desemboca en estas tierras, ha de ser evacuada al mar por un sistema de canales y molinos, único en el mundo.

El país queda así defendido por un sistema costero de diques y dunas fijas, que deben ser 


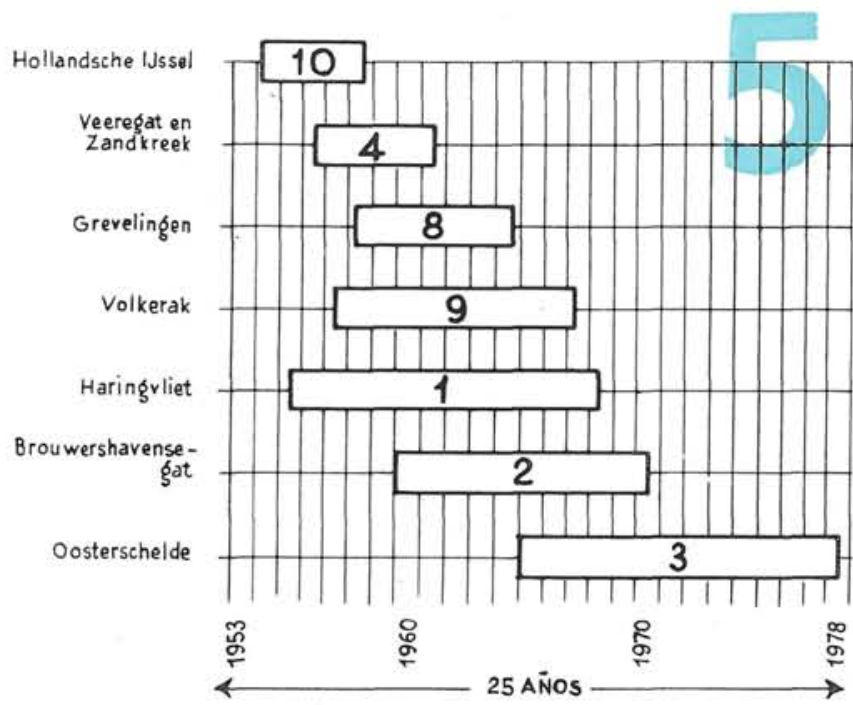

Programa previsto para los cierres del PLAN delta objeto de continuos cuidados, extendido a lo largo de $1.800 \mathrm{~km}$. Es lógico que para reducir los gastos de entretenimiento se haya pensado en acortar las costas cerrando los grandes brazos; pero las limitaciones técnicas no lo hicieron posible hasta el presente siglo.

El mar en varias ocasiones ha superado estas defensas, produciendo inundaciones, que en 1916 y 1953 alcanzaron proporciones catastróficas. En 1916 fueron las aguas del Zuiderzee las que invadieron 60.000 hectáreas del noroeste, y esta catástrofe movió al Gobierno a proyectar la construcción de un dique de $32 \mathrm{~km}$ que cerrara la entrada del golfo (fig. 2). Este dique, construido por el ingeniero señor Lely entre el período 1927-1932, hizo retroceder el mar $85 \mathrm{~km}$, y acortó la línea costera en $300 \mathrm{~km}$. Tras él se formó un gran lago de 225.000 hectáreas, del que la mayor parte ya se ha desecado. El resto, una vez lleno de agua dulce, que le llega del Rin por intermedio del río IJssel, constituye hoy el lago del mismo nombre, depósito de agua dulce del norte del país. Sobre el dique, una gran carretera ha acortado considerablemente las comunicaciones entre el norte y el centro (fig. 3 ).

Desaparecida la preocupación de la parte noroeste, se concentró la atención sobre el suroeste, donde desembocan los ríos Mosa, Waal, Lek y Escalda, formando un gran Delta, en el que el mar penetra profundamente (fig. 4). En 1950 y 1952 se cerraron los brazos de mar, Brielsche Maas (fig. 4, nüm. 15 al norte), comunicando Rozenburg y la isla de Voorne, y el de Braakman (fig. 4, núm. 15 al sur) en el Flandes Zeelandés, en los que se empleó una nueva técnica desarrollada parcialmente en la desecación de la isla de Walcheren (fig. 4, núm. 13), inundada en los bombardeos de 1944.

En febrero de 1953, cuando se estudiaban las mejoras a introducir en las defensas del Delta, sobrevino una inundación que afectó más de 150.000 ha, causó 1.835 bajas humanas y destruyó 47.300 casas, arrasando centenares de kilómetros de diques con unas pérdidas de más de 24.000 millones de pesetas. Gracias a un tremendo esfuerzo, en el que colaboraron el pueblo, el ejército y los técnicos, en menos de un año se logró reparar los diques y desecar las tierras, aunque no pudieron aún ser cultivables.

Esto hizo inminente la necesidad de protección del suroeste. El 21 de febrero del mismo año se estableció la Comisión del Delta para el estudio del plan. Había que tener en cuenta:

el nivel máximo de marea alta previsible, que no es el mismo en cada brazo, y que en algún punto puede alcanzar $5,80 \mathrm{~m}$ sobre el nivel medio, medido en Amsterdam;

la fuerza de los golpes de mar;

la altura de sobreelevación de las olas;

el hundimiento de las costas holandesas, que representa de 15 a $30 \mathrm{~cm}$ por siglo;

y, por fin, la longitud de las costas a defender, que es de unos 700 kilómetros.

Había dos soluciones: reforzar todas las defensas, ganando altura superior a este nivel máximo, o cerrar la entrada de todos los brazos de mar a esta altura. Antes del plazo de un año, la Comisión declaró que, por su seguridad y por las consecuencias económicas que se seguirian, era más ventajosa la segunda, que consideraban técnicamente posible. El 5 de noviembre de 1957, proyectado el plan, la segunda Cámara del Parlamento votó la Ley que prevé los cierres del Delta, cuyas obras abarcarán un período de veinticinco años (figura 5).

Tras este plan, ya en marcha, se estudiará la unión entre si de las islas Wadden al norte (fig. 1) y del conjunto por los extremos al continente, lo cual dejará reducida la costa a una sola línea curva muy simple (Waddenplan).

\section{El plam del Delta}

Es una de las obras más ambiciosas que el hombre ha intentado nunca. Aunque es factor preponderante la defensa costera contra los continuos ataques del mar, al cerrar los brazos de mar, salida natural de grandes ríos, se crea un problema hidráulico cuya solución proporciona una de las ventajas que han motivado la elección. Consta el plan de las siguientes obras:

1." Cierre del brazo de mar de Haringvliet.

2." Cierre del brazo de mar de Brouwershavensche Gat. 
3." Cierre del brazo de mar de Oosterschelde (Escalda Oriental).

4." Cierre del brazo de mar de Veeregat y dique de Zandkreek.

5." Obras en el rio Oude Maas.

6. ${ }^{\text {a }}$ Presas en el Bajo Rin, cerca de Hagestein.

7." Obras de cierre menores (Braakman, Brielsche Maas, etc.).

8." Dique de Grevelingen.

9." Dique de Volkerak.

10. ${ }^{\mathrm{A}}$ Obras del Hollandsche IJssel.

11." Red de carreteras.

Reducirá la costa en $700 \mathrm{~km}$, cerrando todos los brazos de mar, excepto el Westerschelde, entrada natural al puerto belga de Amberes, y el Nieuwe Waterweg, canal de entrada al puerto de Rotterdam; se ganarán unas 15.000 ha de terreno; se creará un gran depósito de agua dulce, que regulará el suministro de este agua al resto del país; se evitarán las infiltraciones salinas tan perjudiciales a la agricultura; y se construirá una amplia red de carreteras que contribuirá al desarrollo de la provincia de Zelanda, hasta hoy bastante aislada.

\section{$1 .^{a}-$ Cierre del brazo de mar de Haringvliet.}

El dique de Haringvliet (fig. 4, núm. 1) une las islas de Goeree y Schouwen, y es de capital importancia para la defensa de Rotterdam. Por el Haringvliet se evacuaba hasta ahora todo el agua del Mosa y el 60 por 100 de la del Rin, a través del Waal. El caudal medio de estos dos ríos es de 300 y $2.200 \mathrm{~m}^{3} / \mathrm{s}$, respectivamente, de la del Rin, a traves del Waal. El cauda mediante el dique llegando el máximo a 2.900 y 13.000 . Esta gran cantidad de agua setterdam, para que salga por el Nieuwe de Volkerak (fig. 4, núm. 9), al futuro lago Delta, o al puerto de Rotterdam, para que salga por el Nieuwe Waterweg (unos $750 \mathrm{~m}^{3} / \mathrm{s}$ ). Sobra aún mucha agua. Además, en la primavera es necesario evacuar los grandes hielos que traen los rios procedentes de su congelación anterior. Por ello, para permitir la salida por este brazo de Haringvliet, el dique tendrá en su centro un grupo de 17 esclusas, con una luz de $56,5 \mathrm{~m}$ cada una, y cuyo fondo se encuentra a $5,5 \mathrm{~m}$ por debajo del nivel medio de mareas. Con barcos rompehielos

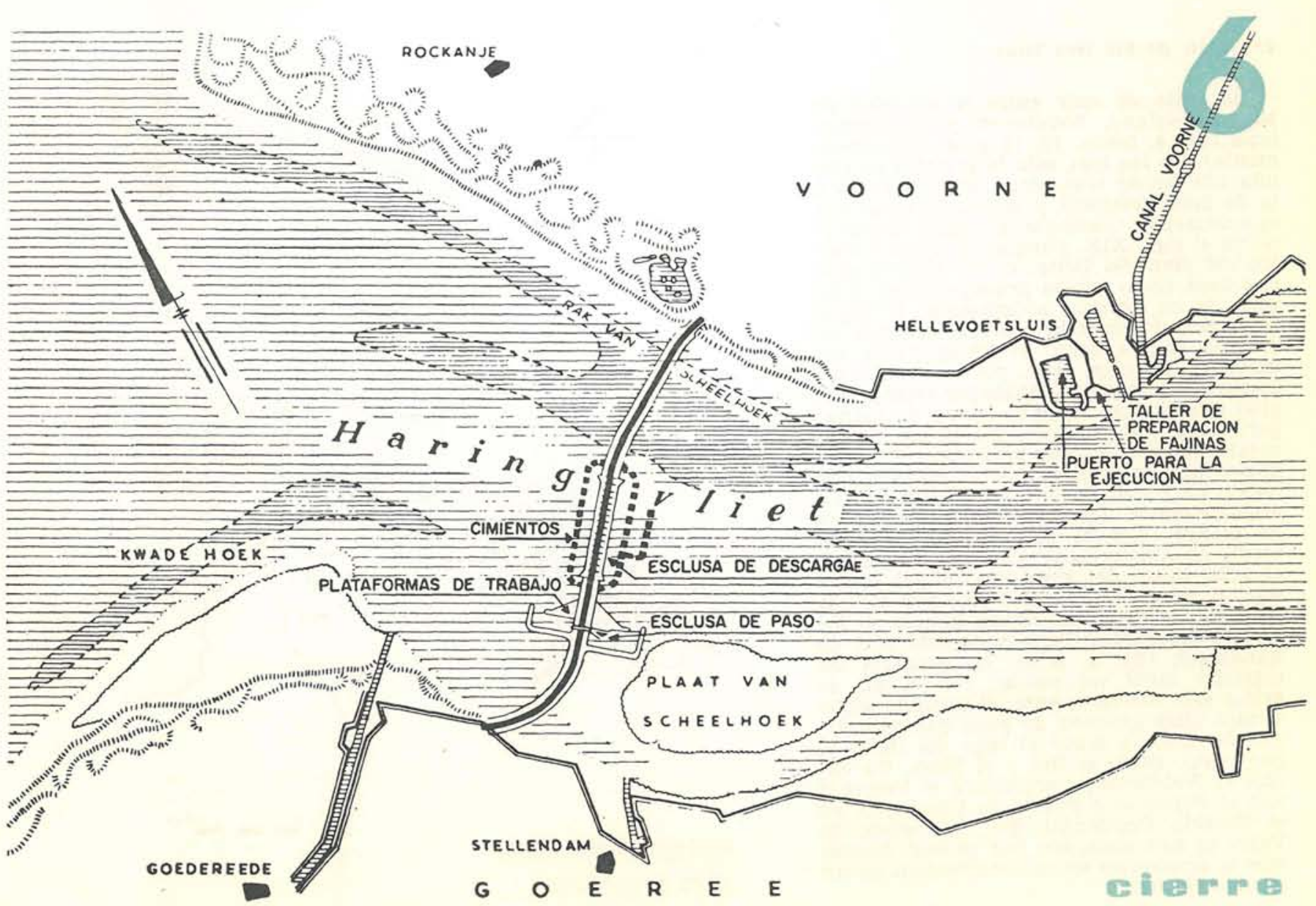


se fragmentarán los posibles bancos formados, y cuando las diferencias de nivel en el mar y el Haringvliet sean las convenientes se abrirán las esclusas, originando una corriente hacia el mar que evacuará los témpanos de hielo.

Como el dique cierra la salida del Mosa, río navegable que viene de Francia y Bélgica, se dotará también al dique de una esclusa de paso para la navegación (fig. 6).

\section{2.a y $3 .^{a}$-Cierre del brazo de mar de Brouwershavensche Gat y Escalda Oriental.}

Son las obras más importantes del plan (fig. 4, núms. 2 y 3), sobre todo el dique del Oosterschelde (8 $\mathrm{km}$ de longitud), en un brazo de mar cuyo fondo alcanza los $40 \mathrm{~m}$ bajo el nivel medio.

Estos diques no tendrán esclusas, y para su construcción se emplearán nuevos métodos que se han ensayado recientemente en el dique del veeregat (cuarta obra). Probablemente, serán dotados de sifones de bombeo, que saquen hasta las capas más profundas del agua (mayor contenido salino) y la expulsen al mar en la marea baja. Los sifones quedarán, una vez concluido el lago, para renovar el agua dulce del fondo que, por filtración, tenderá a salinizarse.

La construcción encierra grandes dificultades. Los brazos de mar están unidos entre sí, con lo que las dos olas de flujo se encuentran a la altura de Bruinisse (fig. 4, núm. 8) (no exactamente, pues varía con la altura de la marea y otras condiciones), originando una superficie de separación desde la que horas más tarde parte la corriente de reflujo. En este lugar no tiene el mar actividad ninguna; pero si uno de los dos brazos se cierra, la corriente de flujo, que entra por el otro, no encuentra ningún freno y, consecuentemente, pasará al primero, incrementando la velocidad y originando una fuerte erosión muy perjudicial en el suelo y en las paredes, generalmente de arena. Para que esto no ocurriera tendrían que construirse los dos diques al mismo tiempo, cosa que la envergadura de las obras no permite. Se ha optado por construir antes la obra octava, levantando, en el emplazamiento más frecuente de la superficie de separación de las dos olas, un dique, el de Grevelingen (fig. 4 núm, 8), que separe los brazos de mar y que deje, en el mismo punto en que ahora está, el fin de la ola de flujo del brazo abierto. Este dique tendrá esclusas de navegación, que serán necesarias tanto en el momento de los trabajos en el dique que se cierra como cuando el lago esté concluido.

\section{4. a-Plan de las tres islas.}

Se trata de unir entre sí las islas de Noord-Beveland, Walcheren y Zuid-Beveland (fig. 4, núms. 12, 13 y 14, respectivamente). De las tres, sólo la primera es aún una isla. La de Walcheren está unida ya a la de Zuid-Beveland, y ambas lo están con el continente, mediante un dique construido en el siglo XIX. Aunque se engloba dentro del plan del Delta, es un plan aparte, que tiene como misión principal sacar a las islas de su antiguo aislamiento. El dique de Veeregat cierra la entrada del mar en el paso (fig. 4, núm. 4) Se apoya en las defensas actuales, que, por la parte del Onrustpolder son suficientes por estar protegido éste por un extenso banco de arena; pero no por el lado opuesto, al que es necesario darle una gran protección. El dique presentará un trazado con rompeolas, con objeto de cortar las líneas de corriente en ángulos rectos. Aquí se da la mayor altura de marea $(5,40 \mathrm{~m}$ por encima del nivel medio en Amsterdam), y, cuando se cierre, el gran brazo del Escalda Oriental estará aún incrementado en $0,40 \mathrm{~cm}$; por esto se ha dado al dique una altura basada en los $5,80 \mathrm{~m}$ previsibles. Terminado éste y el de Zandkreek (fig. 4, núm. 7), quedaría un estrecho canal sin salida; con el fin de evitar este inconveniente, el segundo dique tendrá unas esclusas de paso que permitirán la entrada desde el lago del Delta y, por tanto, desde el Rin y el Mosa. Un canal, el Walcheren, comunicará el Veeregat con el importante puerto de vlissingen, en el Escalda Occidental. En este dique de Veere se han ensayado por procedimientos que se emplearán en la construcción de los grandes diques.

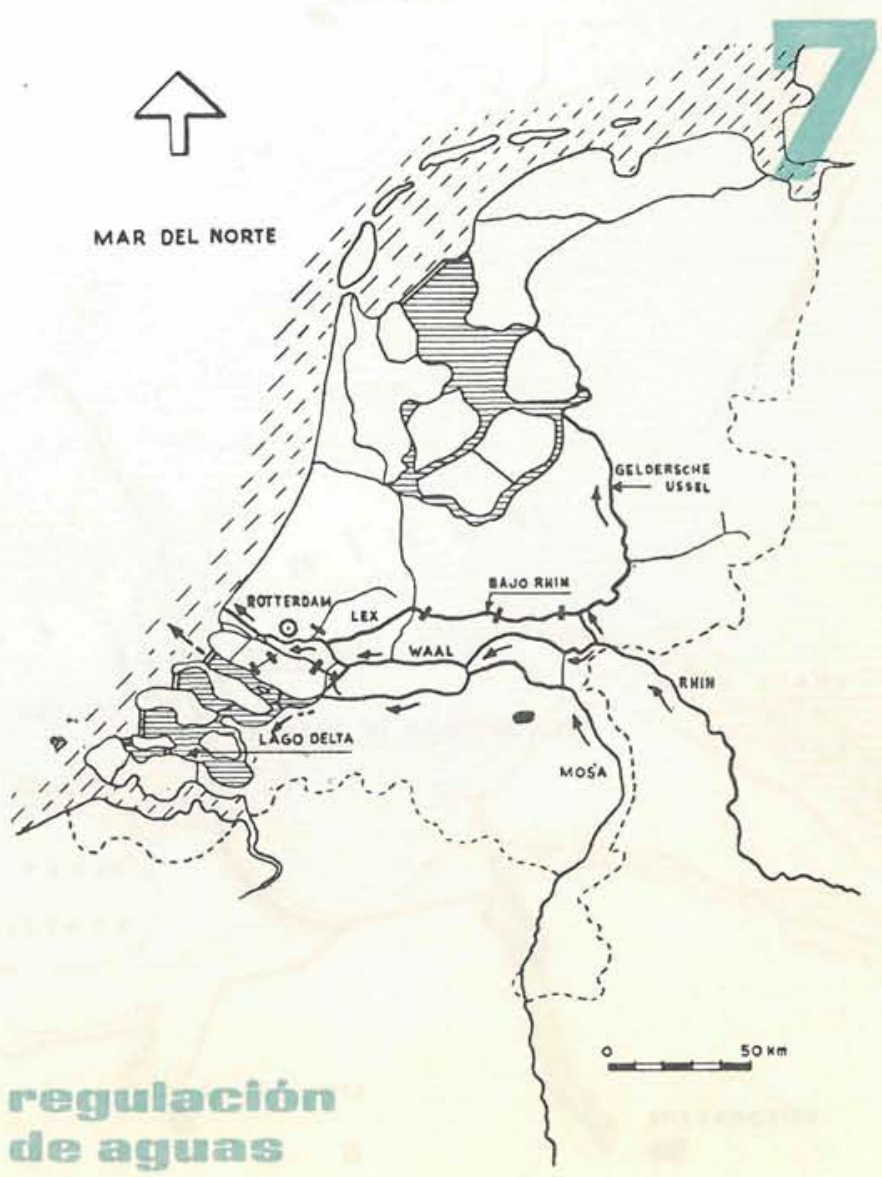




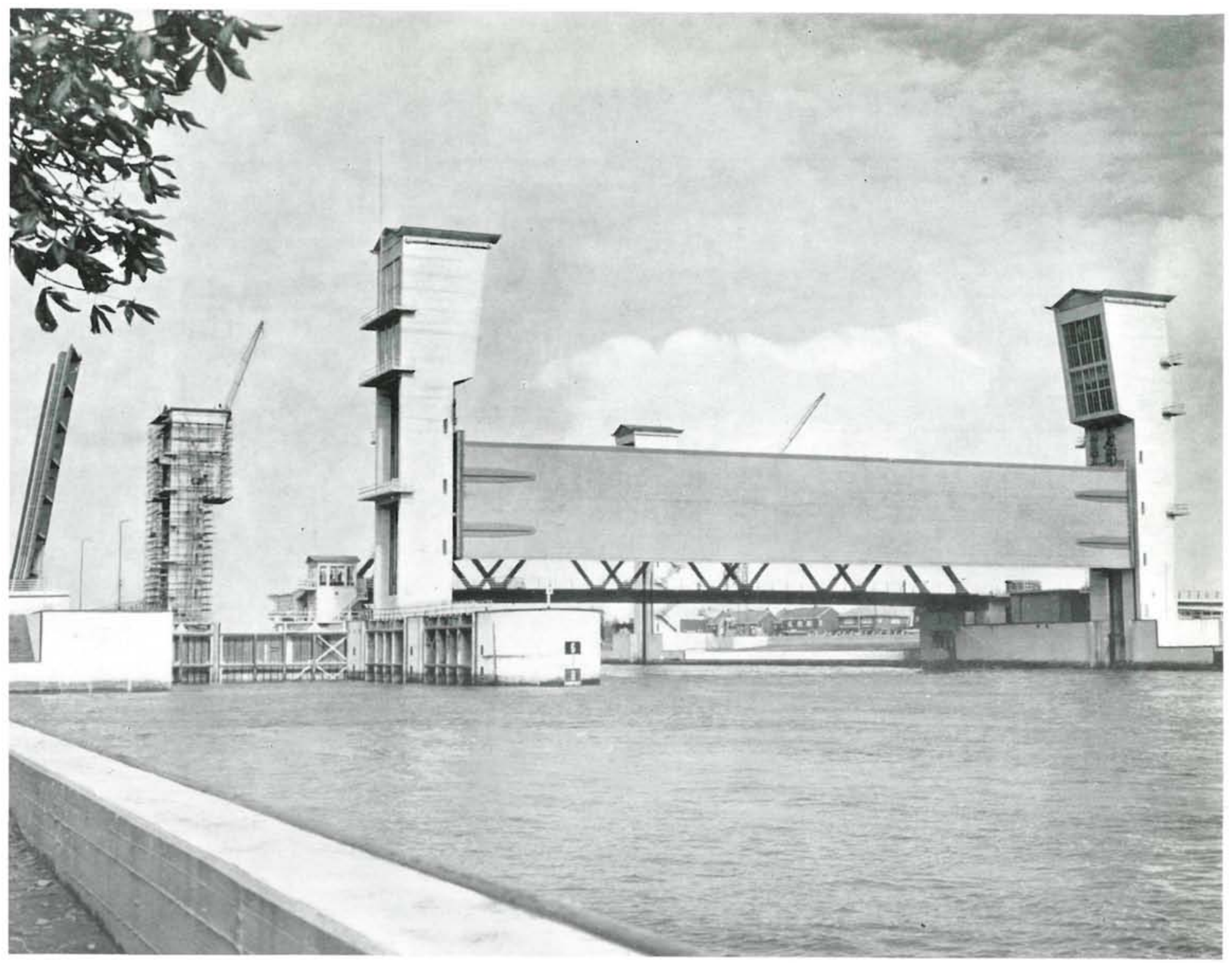

15.

Esselusa en el río IJssel.

5. ㄷobras en el río Oude Maas (fig. 4, núm. 11).

Por el Nieuwe Waterweg (fig. 4, núm. 5) el agua del mar entra actualmente hasta Rotterdam, sedimentando en el suelo y paredes del canal una capa de sales que, por filtración, salinizan una de las zonas agrícolas más importantes. El 50 por 100 del agua dulce que llega al Haringvliet se pierde inútilmente en el mar, pero cuando este brazo esté cerrado será posible enviarla, en gran parte, por el Dordtsche Kil (fig. 4, número 16) y el Noord (fig. 4, núm. 17) a unirse con la que por el Lek viene del Rin, para pasar finalmente por Rotterdam y salir al mar por el canal. Esto hará retroceder el limite de agua dulce (=superficie de agua con $300 \mathrm{mg}$ de $\mathrm{Cl} /$ litro) hacia el oeste; pero tiene la contrapartida de tener que cerrar el Oude Maas, por donde parte del agua se evacuaría sin pasar por Rotterdam. Es un inconveniente, porque, al ser la marea particularmente alta en el canal, conviene tener caminos por donde repartirla y absorberla. El problema se resuelve dotando al Oude Maas de un dique con compuertas y esclusas de navegación. Las compuertas permanecerán normalmente cerradas; si el nivel de marea del Nieuwe Waterweg es muy alto, se abríán automáticamente para permitir el paso. También estarán abiertas en circunstancias favorables, cuando el caudal de agua dulce sea muy grande y la marea baja, para permitir la navegación; el resto del tiempo ésta tendrá que hacerse por las esclusas.

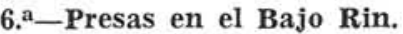

Al disponer del agua del Mosa y del Waal, no es necesario que se envíe tanta agua del Rin hacia Rotterdam; por tanto, se podrá enviar por el río IJssel, mejorando el nivel del lago del mismo nombre. Para ello se está construyendo en el Bajo Rin una serie de tres presas de regulación con esclusas para la navegación (figura 7). 


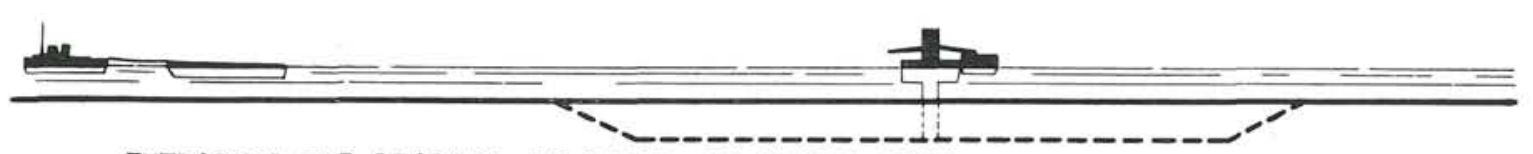

EXTRACCION POR DRAGADO, DE CAPAS DE TIERRA DEBIL
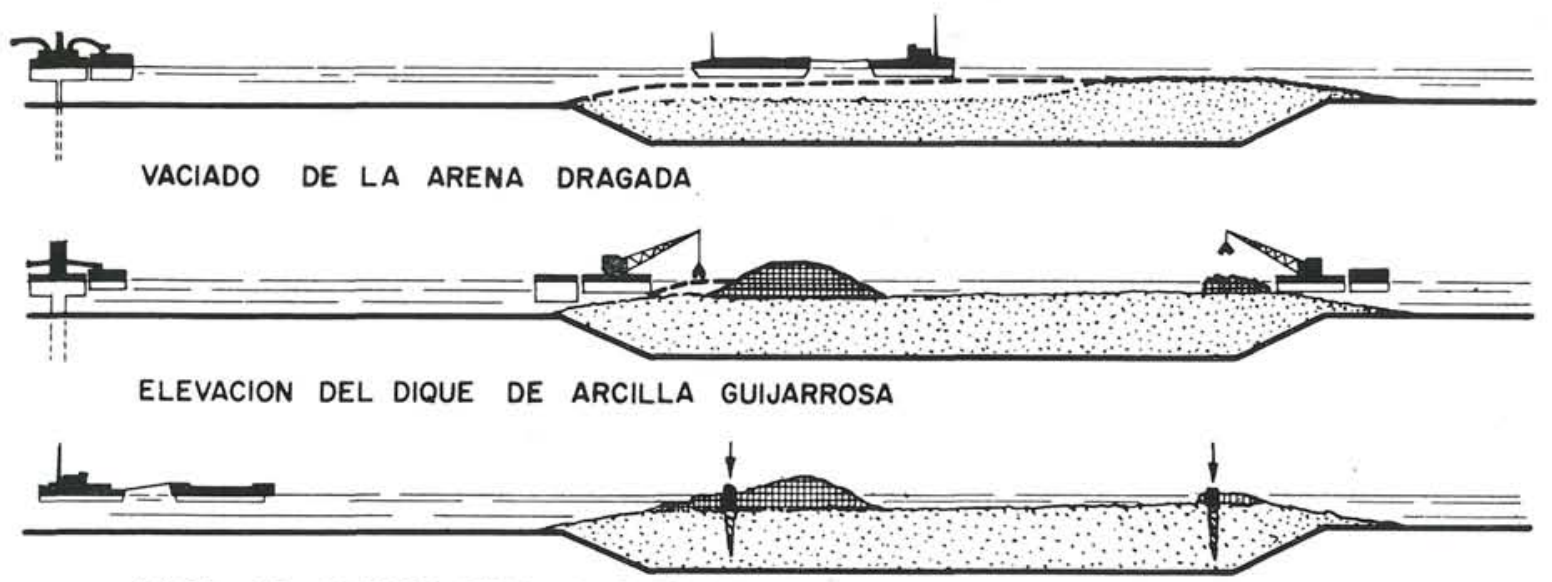

HINCA DE PILOTES PARA LA ESTRUCTURA
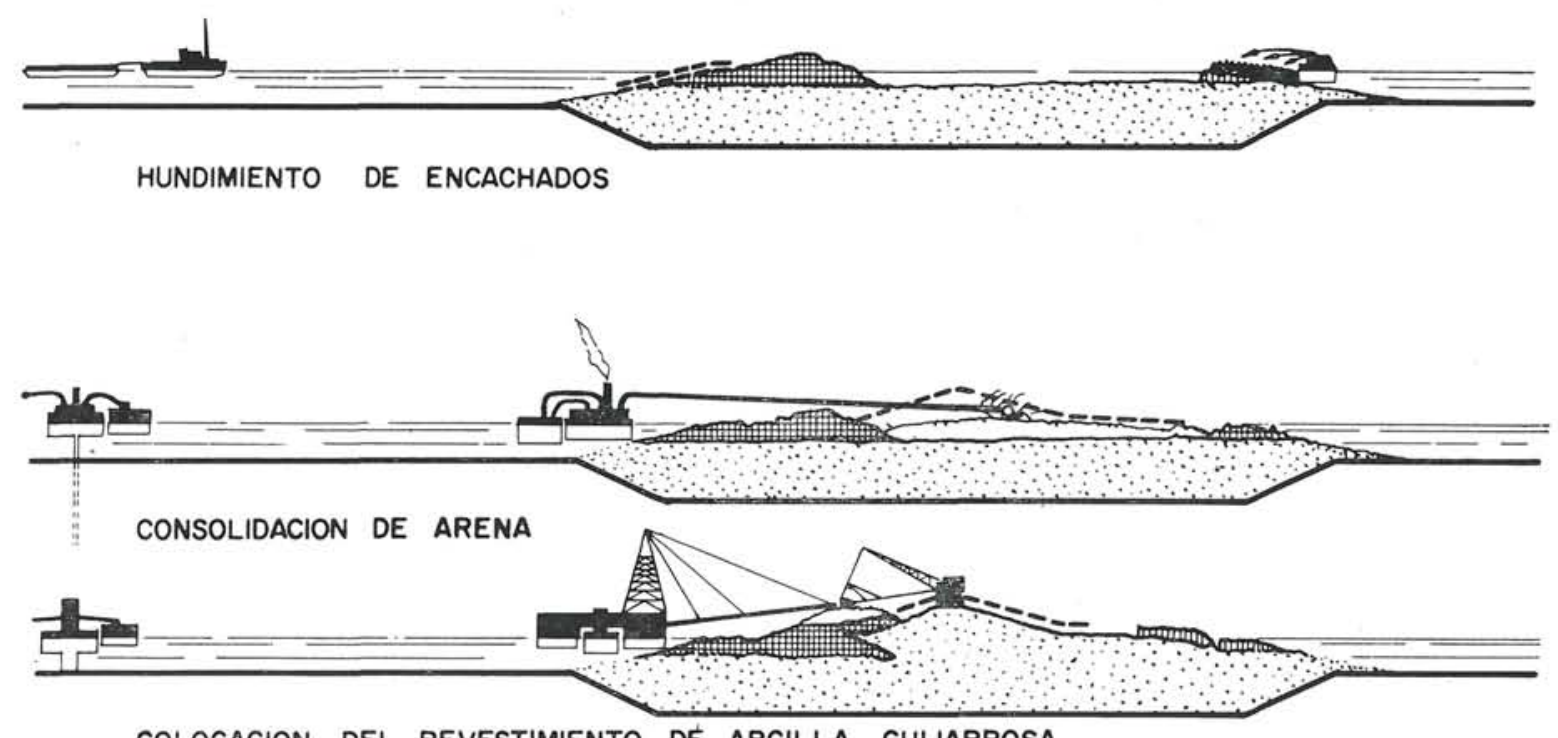

COLOCACION DEL REVESTIMIENTO DE ARCILLA GUIJARROSA
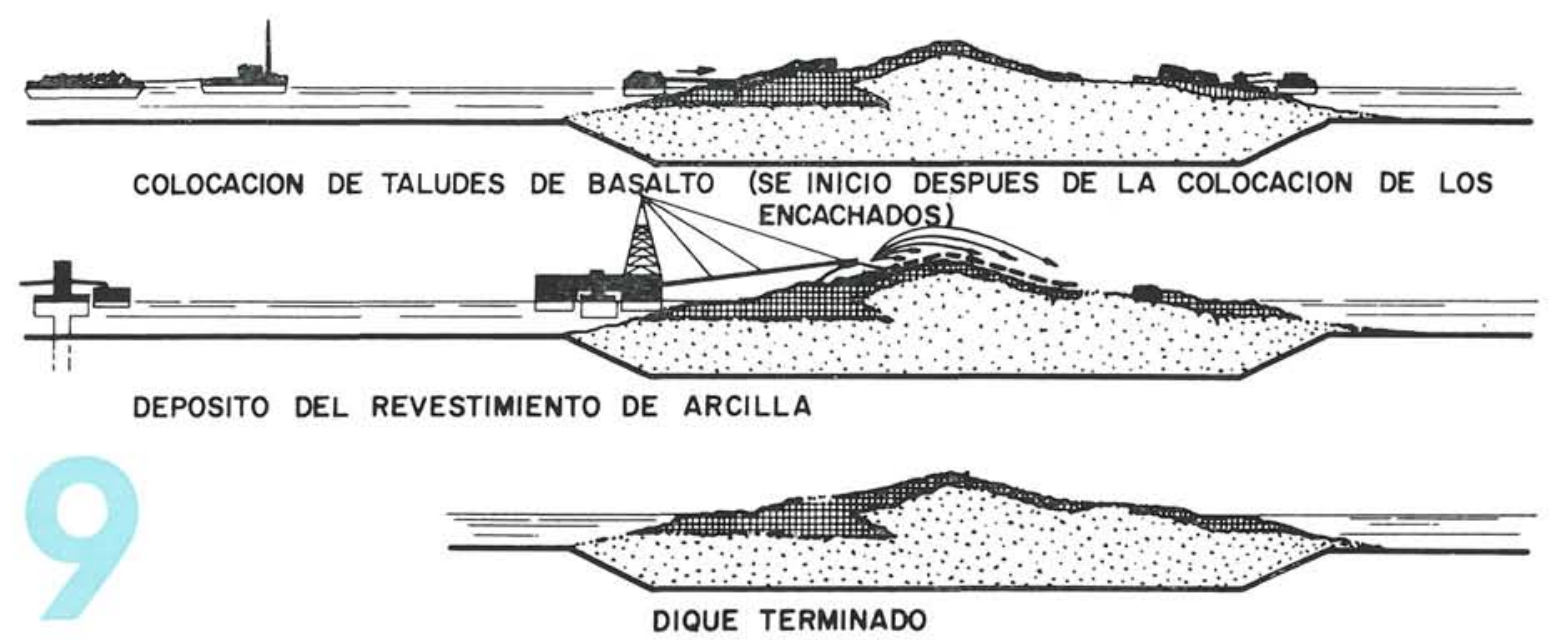
$7 .^{a}$-Obras de cierre menores.

En estas obras se incluyen las ya efectuadas, el refuerzo de las paredes del Nieuwe Waterweg y el mejoramiento de las defensas de dunas y diques del Delta y Elcalda Occidental.

\section{8. ${ }^{a}$-Dique de Grevelingen.}

Este se menciona en las obras segunda y tercera.

\section{9. ${ }^{\text {- }-D i q u e ~ d e ~ V o l k e r a k . ~}$}

Todo el complicado sistema funciona gracias al dique de Volkerak (figura 4, núm. 9), que actúa como válvula triple, regulando la entrada del agua del waal y del Mosa y dirigiéndola, según las necesidades, al lago (lago Zeelandés) para constituir la reserva hacia Rotterdam, o hacia el Haringvliet cuando sea necesaria la evacuación de hielos. El dique de tres ramas tendrá vertederos y amplias esclusas de navegación.

\section{0. a-Obras del Hollandsche IJssel.}

La más urgente y ya concluida obra es la del cierre de este río (fig. 4, núm. 10), que desemboca al este de Rotterdam en el canal, procedente de la fértil llanura holandesa, y que en muchas ocasiones ha servido de camino al mar en marea alta que inundó las tierras. Se ha construido una gran presa con compuertas, que serán cerradas cuando las condiciones sean desfavorables (fig. 8).

\section{1. a-Red de carreteras.}

Finalmente, por todas las presas se construirán carreteras que formarán una extensa red, acortando todas las distancias.

Las mejoras sociales y económicas no se harán esperar. Rotterdam ya es el segundo puerto mundial después de Nueva York, y actualmente se proyecta el Europort, que convertirá en puerto la totalidad de las riberas del Nieuwe Waterweg, y para el cual se ha empezado a montar nuevas refinerías y grandes fábricas, al mismo tiempo que se construyen enormes bloques de viviendas, que puedan albergar a las personas que, indudablemente, vendrán a la zona atraídas por el plan.

\section{Las obras}

Los diques de cierre normales están constituidos por un gran núcleo de arena revestida de arcilla. La parte que baña el agua se reviste, generalmente, de basalto; por debajo de la zona de actividad, es decir, del nivel de bajamar, se encacha con fajinados de mimbre, y por encima del nivel máximo alcanzado por las olas - teniendo en cuenta la sobreelevación del choque-se reviste de césped. La altura máxima del dique está determinada por este nivel en la marea viva más desfavorable que se prevea. En la berma externa se construyen los rompeolas, $\mathbf{y}$ en la interna, una carretera.

En un brazo de mar existente en una zona de mareas se ha llegado a un perfil, en el que están en equilibrio la resistencia de fondo y paredes con la erosión causada por las velocidades de las olas de flujo y reflujo. Si se va cerrando mediante diques este brazo, al disminuir el perfil lateral, la velocidad se va incrementando y el equilibrio tiende a restablecerse erosionando el fondo. Esto tiene un límite. A la distancia que queda entre los diques que se acercan desde las orillas en el límite, se denomina apertura de cierre.

El método clásico de construcción (fig. 9) consiste en proteger la línea de cierre, dragando la tierra débil y encachando el fondo con grandes fajinadas de mimbre, que se transportan flotando hasta su lugar de emplazamiento, hundiéndolas por medio de lastres de piedra. La solidez y resistencia del encachado es mayor a medida que se separa de las orillas, y máxima en la apertura de cierre. Actualmente se ensayan protecciones de láminas de asfalto, materiales plásticos, etc.

Inmediatamente se vacía sobre la protección, a partir de las orillas, una gran cantidad de arena, fabricando una especie de torta, y en sus bordes se empieza a construir un pequeño dique que ya emergerá del agua. Este dique es de arcilla guijarrosa y en él se clavan unos largos postes de hormigón armado, por medio de martillos especiales, que formarán la estructura; las bermas se protegen inmediatamente por fajinas y se procede a construir las protecciones de basalto. Mientras tanto se rellena el dique entre los bordes con arena, hasta que se forma el núcleo de altura requerida; después se protege la arena con arcilla compacta, asfalto, etcétera. Así se llega a la apertura de cierre. Entonces hay que esperar a un período de marea baja y cerrar en una sola operación. Este cierre se procura que sea mínimo (hasta ahora unos $300 \mathrm{~m}$ ) y se efectúa con arcilla o, en las mayores, con grandes cajones de hormigón flotantes, que se emplazan con remolcadores y se hunden a la vez. Por razones de construcción, estos cajones no pueden pasar de ciertas dimensiones. Los mayores, empleados en el desembarco de Normandia, son los del tipo Phoenix $(16,18 \times 18,90 \times 18,29 \mathrm{~m})$.

Estos métodos, no obstante, sólo son posibles si la apertura es suficientemente pequeña, o pasa por ella poca agua. El cierre mayor que se ha hecho con cajones tipo Phoenix es el de Ouwerkerk, que llegó posiblemente al máximo de posibilidades. Llamando capacidad de un perfil a la cantidad de agua que lo atraviesa 


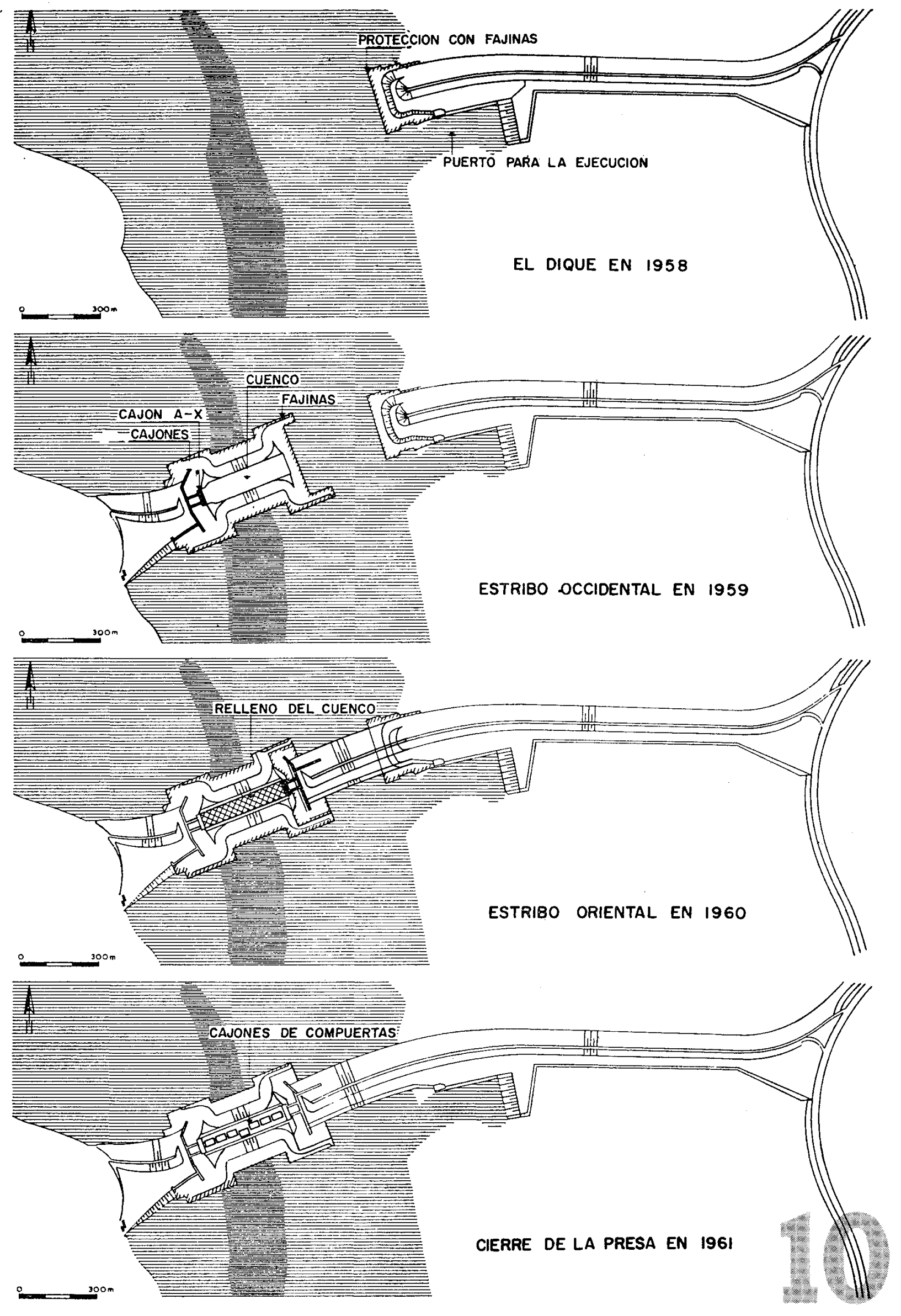


en un periodo de flujo y reflujo en ambos sentidos, el Ouwerkerk tuvo una capacidad de 90 millones de $\mathrm{m}^{3}$. En los brazos del Delta la capacidad es considerablemente mayor: el Haringvliet tiene 500 millones de $\mathrm{m}^{3}$; el Brouwershavensche Gat, 600, y el Escalda Oriental, 2.000 millones de $\mathrm{m}^{3}$. Ante esto han tenido que ensayarse nuevos métodos que se emplean en las obras actualmente en desarrollo.

\section{a) Obra del Veeregat (fig. 10).}

Se ha terminado este cierre, como estaba previsto, en cuatro años, uniendo las dos islas citadas. En el primer año se reforzó la duna y viejo dique del Onrustplaat, construyendo un sólo dique y, sobre él, una pista ciclista y una explanación para la futura gran carretera. Se preparó un puerto de trabajo, que ocupa $7.500 \mathrm{~m}^{2}$ con una profundidad de $5,5 \mathrm{~m}$ bajo el nivel del mar, construido hacia el continente por medio de grandes cajones de hormigón de un peso de $50 \mathrm{t}$, que se rellenaron posteriormente de piedra. Y finalmente se profundizó la línea de cierre por donde se construiría el dique, como resultado de ensayos en laboratorio, hasta $14 \mathrm{~m}$ bajo el nivel medio. El pie del dique se ha reforzado, de una manera nueva, colocando grandes losas de hormigón, contra las cuales se han sujetado dos bandas impregnadas de nylon. Sobre ellas una capa de asfalto que sube hasta lo más alto del dique, ganando espesor.

El segundo año se continuó el dique del onrustplaat hasta una longitud de $900 \mathrm{~m}$, encachando y estabilizando el fondo de la linea de cierre.

El tercer año se empezó la construcción del dique desde Walcheren y se continuó desde Onrust hasta formar la apertura de cierre, que tenia un perfil de $3.850 \mathrm{~m}^{2}$, con una profundidad de $11 \mathrm{~m}$ bajo el nivel medio.
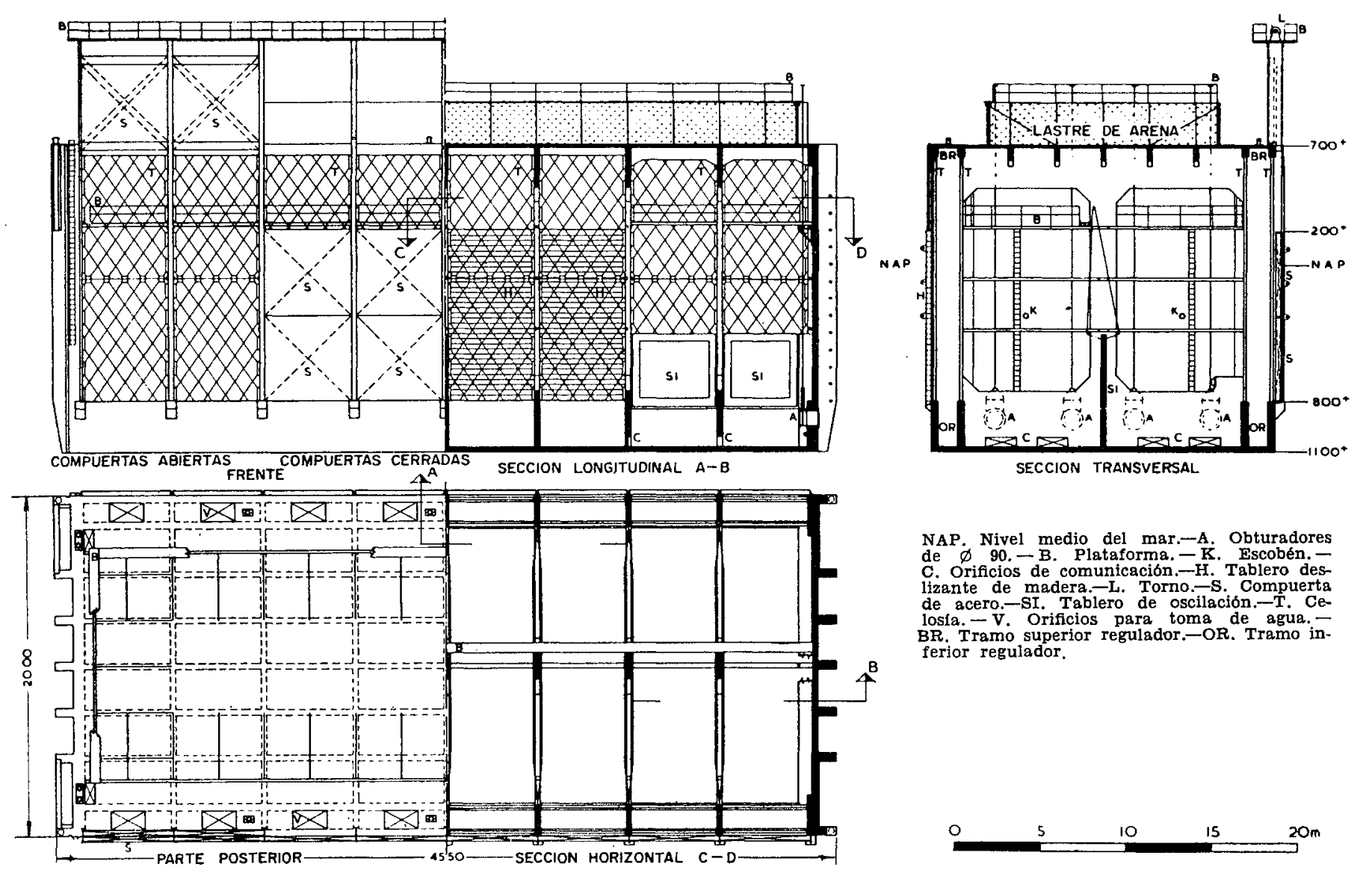

NAP. Nivel medio del mar.-A. Obturadores de $\varnothing$ 90, - B. Plataforma. - K. Escobén. C. Orificios de comunicación.-H. Tablero deslizante de madera.- L. Torno.-S. Compuerta de acero.-SI. Tablero de oscilación.-T. Celosia. - V. Orificios para toma de agua. regulador.-OR. Tramo in ferior regulador.
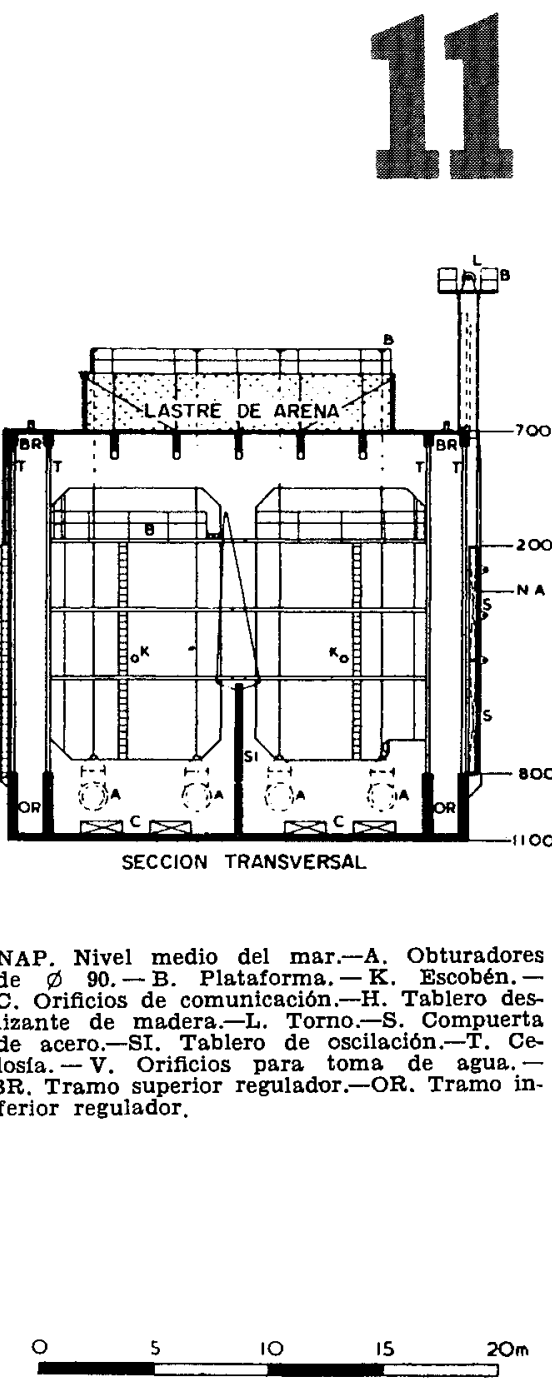

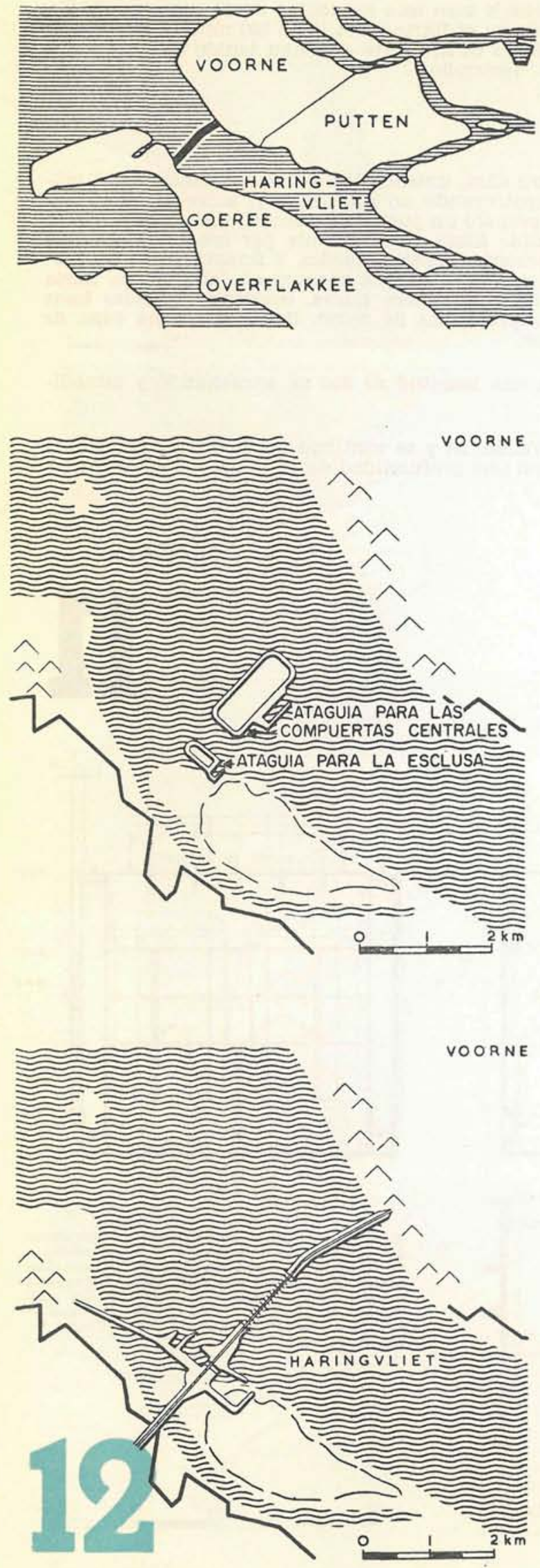

El cuarto año se procedió al bloqueo definitivo de la apertura de cierre; se terminaron de unir los diques construidos a este fin, y se concluyó la obra el 27 de abril de 1961. Ya se ha dicho que, con vistas a los grandes diques, cuya apertura de cierre no podrá hacerse de un solo golpe, se ha ensayado un original método en el Veeregat. Consiste en colocar en la apertura de cierre un número de grandes cajones huecos de hormigón que dejan pasar el agua sin obstáculo a través de ellos. De esta manera la velocidad del agua en la apertura queda invariable, mientras se colocan y enclan los cajones, que forman una especie de muelle de esclusas. Después, y por un dispositivo especial, se cierran los cajones en una sola jornada, constituyendo un primer dique provisional, sobre el cual se construye el definitivo.

Antes de proceder al cierre se hace la obra de unir los dos ramales de dique a la armadura de cajones, usando otros pequeños cajones del tipo de los utilizados en la construcción del puerto de trabajo.

Los grandes cajones especiales (fig. 11) tienen una estructura de hormigón, de $45,5 \mathrm{~m}$ de longitud en el sentido del dique por 20 de anchura y 18 de altura; interiormente van divididos en compartimientos por medio de paredes perpendiculares al frente, que se transmiten el empuje entre sí por vigas transversales a altura superior al nivel más alto de mareas, con objeto de no provocar resistencia a las corrientes. Estas paredes llevan taladros para permitir al agua distribuirse dentro del cajón. Los dos frontales están constituidos por dos enrejados paralelos, a base de gruesas barras de hierro en diagonal. Estos vanos pueden obturarse con ocho compuertas, divididas en dos en sentido de la altura para mayor manejabilidad.

El cajón se ha construido en un foso, cuyo fondo está ligeramente más bajo que el nivel de marea alta, y aislado del mar por un dique. Cuando está terminado, se obturan las compuertas, y en un período de alta mar se abre el dique, sacando el cajón flotando y por medio de remolcadores se le sitúa en su sitio. La estabilidad en la marcha se halla garantizada por un tablero oscilante en el eje mayor, que se rebate cuando esté colocado para permitir el paso de la corriente.

Una vez colocado, se lastra el fondo con arena para hacer aumentar la altura metacéntrica, bajando el c. de $\mathrm{g}$. Entonces se abren las compuertas, y el cajón, por su propio peso, se hunde hasta apoyarse en la protección del suelo. El hundimiento lo realiza horizontalmente, porque la altura del c. de g. es muy pequeña; el equilibrio se lo proporciona su simetria, y como las paredes interiores van perforadas, puede el agua circular sin obstáculos. Una vez apoyado el cajón en el suelo, se rellena de arena un gran compartimiento destinado a ello en la parte superior, con lo que el cajón permanece perfectamente fijo al suelo, quedando arriba un camino de $14 \mathrm{~m}$ que se utiliza durante los trabajos. Ya fijo, se rellena de grava el suelo delante y detrás del cajón, lo que absorberá pasivamente parte de la intensidad de las corrientes.

Colocados todos los cajones, y anclados entre sí, se terminan de construir los diques en su unión a los cajones, se espera a un período de bajamar, y se dejan caer todas las compuertas. Cuando la ola de flujo vuelva, se encontrará ya con un dique. Como entre el mar y el lago interior formado existe una diferencia de nivel en este momento, de mar a tierra se ejercerá un empuje hidráulico que debe ser absorbido por el cajón, sus lastres y el agua que habrá quedado encerrada en él. Para que el empuje sea mínimo, se abren unos vertederos y se deja al lago tomar el nivel medio del mar, cerrándolos apenas se haya logrado el objetivo deseado. Después de este cierre se rellenan de sacos de arena los espacios entre las rejillas metálicas y, posteriormente, se recuperan las compuertas y se sustituyen por vigas de hormigón. Sobre este dique como núcleo, se construye el definitivo por el procedimiento ordinario. Según cálculos, la recuperación del cajón costaría tanto como la fabricación de uno nuevo $\mathrm{y}$, por consiguiente, se le dejará formando una armadura en el interior. 


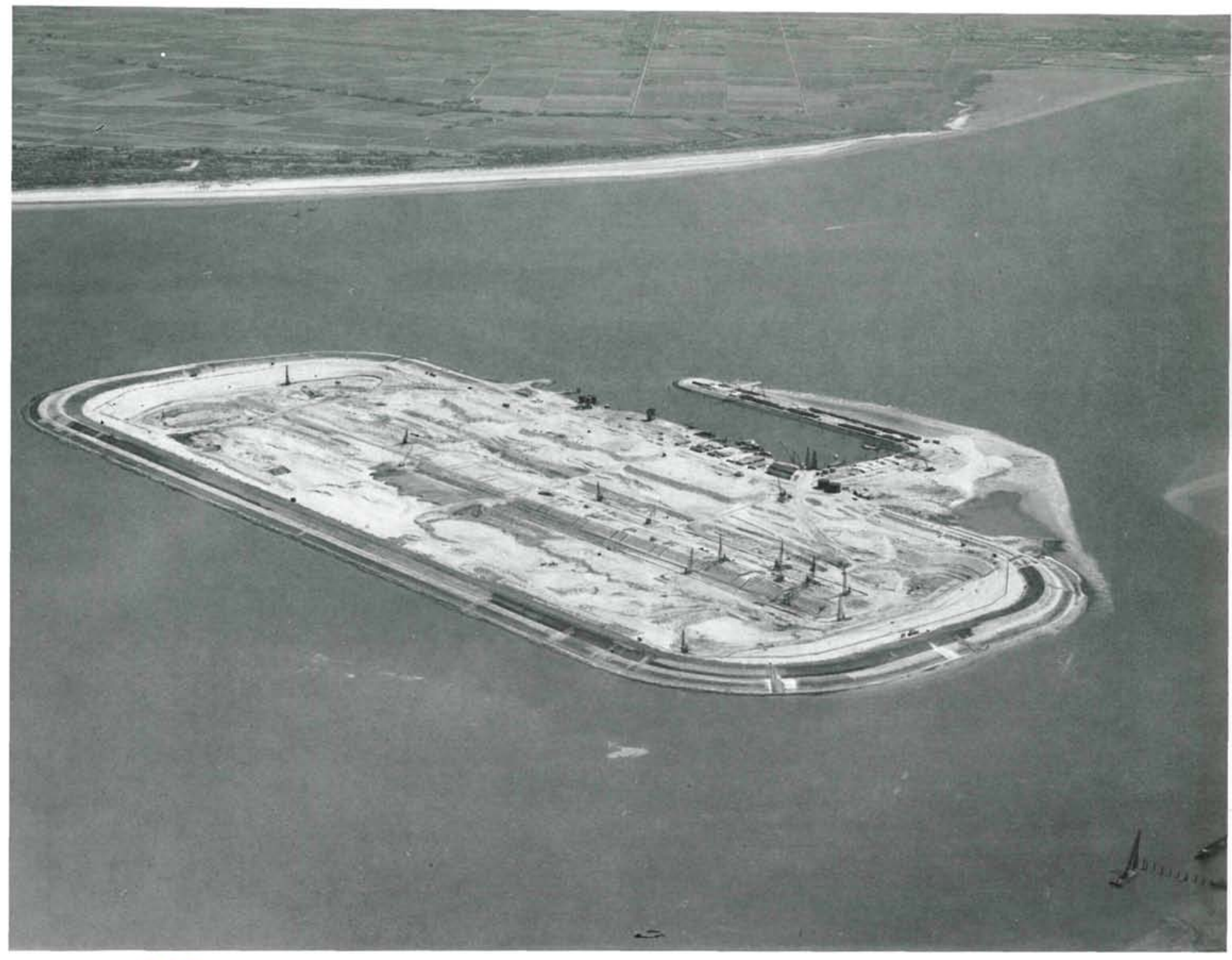

\section{b) El Haringvliet (fig. 12).}

La construcción de este dique tiene que ser especial por el complejo de 17 esclusas que en total miden más de un kilómetro de largo. Se ha decidido construir primero las esclusas y dejar abierto el resto del paso, para cerrar el dique cuando las esclusas estén ya funcionando. El primer jalón ha sido construir una isla artificial en el paraje de menos profundidad, un banco de arena al oeste de la pequeña villa de Hellevoetsluis. Posteriormente se construirá otra, para la esclusa de paso. La forma de la isla artificial fue determinada mediante ensayos efectuados en el labcratorio hidráulico "De Voorst».

Los trabajos del dique se calculan entre los años 1955 y 1968. En principio se ha comenzado por construir un puerto de trabajo y almacenaje en la costa, junto a Hellevoetsluis, que cubre 16 ha, poco más o menos como el pequeño pueblo, y que se realizó entre agosto de 1955 y octubre de 1956 . Terminado éste se comenzó la isla artificial en febrero de 1957 (fig. 13). Primero se ha construido un gran anillo de arena, de altura que oscila entre 4,5 y $8 \mathrm{~m}$, suficiente para prever una altura de marea de $2,5 \mathrm{~m}$ (una vez cada cincuenta años). El dique ha sido reforzado, como de ordinario, con fajinados, y cubierto de una capa de asfalto de $20 \mathrm{~cm}$ de espesor. Se construyó en siete meses, y después se vació el agua y arena débil por dragados. Los costados interiores se han sembrado para evitar el polvo, nubes de arena, etcétera. En el interior de esta isla se efectúan, en la actualidad, los trabajos de construcción de las esclusas (fig. 14). En el costado que mira al continente se ha construido otro puerto, de recepción de materiales, dotado de grúas de carga y descarga, etc. Hasta ahora se ha afianzado el suelo, donde ha de construirse, clavando grandes pilotes de hormigón, y se han acumulado los materiales necesarios para la construcción. Entre éstos, como más interesante, podemos citar un sistema de bombeo para dragar la arena del banco sobre el que se trabaja durante todo el tiempo previsto (seis años). Este se hará por medio de 1.400 pozos, evacuando $6.000 \mathrm{~m}^{3}$ de agua por hora. Para ello ha sido necesario montar una central eléctrica, de una capacidad de $7 \times 650$ C.V.A. ó 7.000 CV., capaz de suministrar una ciudad de 100.000 habitantes. Amén de sus cisternas de petróleo, etc. 
La llegada de agua dulce se realiza desde el continente a la isla por medio de un tubo de plástico (tileno) de $10 \mathrm{~cm}$ de diámetro, con dos cisternas de almacenaje.

Solamente los trabajos preparatorios para empezar la construcción han costado 220 millones de pesetas.

Actualmente se ha construido la plataforma de basamento y pilares de las compuertas, así como el puente que se apoya sobre estos pilares y que servirá de soporte a los ejes de aquéllas, las cuales serán de tipo giratorio y han de contener, las de un lado, el empuje del agua dulce que no ha desembocado, y las del otro, el empuje del agua del mar con los embates de los temporales. Este puente, denominado puente Nabla del plan Delta, lo describiremos a continuación:

\section{El puente Nabla del plan Delta, de hormigún pretensado}

C. Fernández - Casado, ingeniero de caminos

Este puente, de 17 tramos de $60 \mathrm{~m}$ de luz, resulta fuera de lo normal, no sólo por estas características extraordinarias, sino porque, además de servir a la circulación de carretera con $22,80 \mathrm{~m}$ de anchura, ha de soportar todo el empuje de las compuertas, que contendrán: de un lado, las aguas del mar y, precisamente, en época de fuertes temporales; y del otro, las aguas del Haringvliet, uno de los brazos más importantes de la desembocadura, en Delta, común al Rin y al Mosa.

La presa del Haringvliet tiene que regular la circulación hidráulica en este brazo del Delta de modo que pueda quedar cortada la comunicación cuando el nivel del mar en marea alta o temporal ponga en peligro de inundación las tierras bajas del sudoeste de Holanda, costando una catástrofe a la de febrero de 1913. Esto se conseguirá mediante dos compuertas cilíndricas de sector horizontal, una, del lado del mar y otra del lado del río, que han de soportar la diferencia de nivel con solera y aquélla, además, la acción del oleaje. El puente sirve de soporte a los ejes de estas compuertas, transmitiendo todo el empuje a las pilas, lo cual da lugar a acciones inclinadas de gran intensidad, que pueden llegar a $220 \mathrm{t} / \mathrm{m}$ del lado del mar y a 100 en el otro costado. Es preciso tener en cuenta que el peso propio da una carga de $125 \mathrm{t} / \mathrm{m}$.

Se estudiaron distintas soluciones de pilas y puente de acuerdo con el sistema de compuertas empleados, que, al principio, eran verticales deslizantes y después giratorias de sector. En esta última solución, que fue la definitiva, se examinó primeramente la solución de compuertas con sustentación independiente de los dinteles del puente, pero se adoptó la de situar los ejes de giro de aquéllas en los costados de éstos. En estas condiciones se estudiaron tres variantes con dinteles dobles, de sección rectangular, y una con dintel único, de sección Nabla, que fue la elegida. La organización estructural de esta gran nabla requirió todavía una serie de estudios, hasta llegar a la simplicidad geométrica de la adoptada.

El puente consta de 17 tramos independientes, simplemente apoyados sobre pilares mediante articulaciones de caucho. Los dinteles de sección constante, salvo los refuerzos en las zonas de transmisión de empujes,

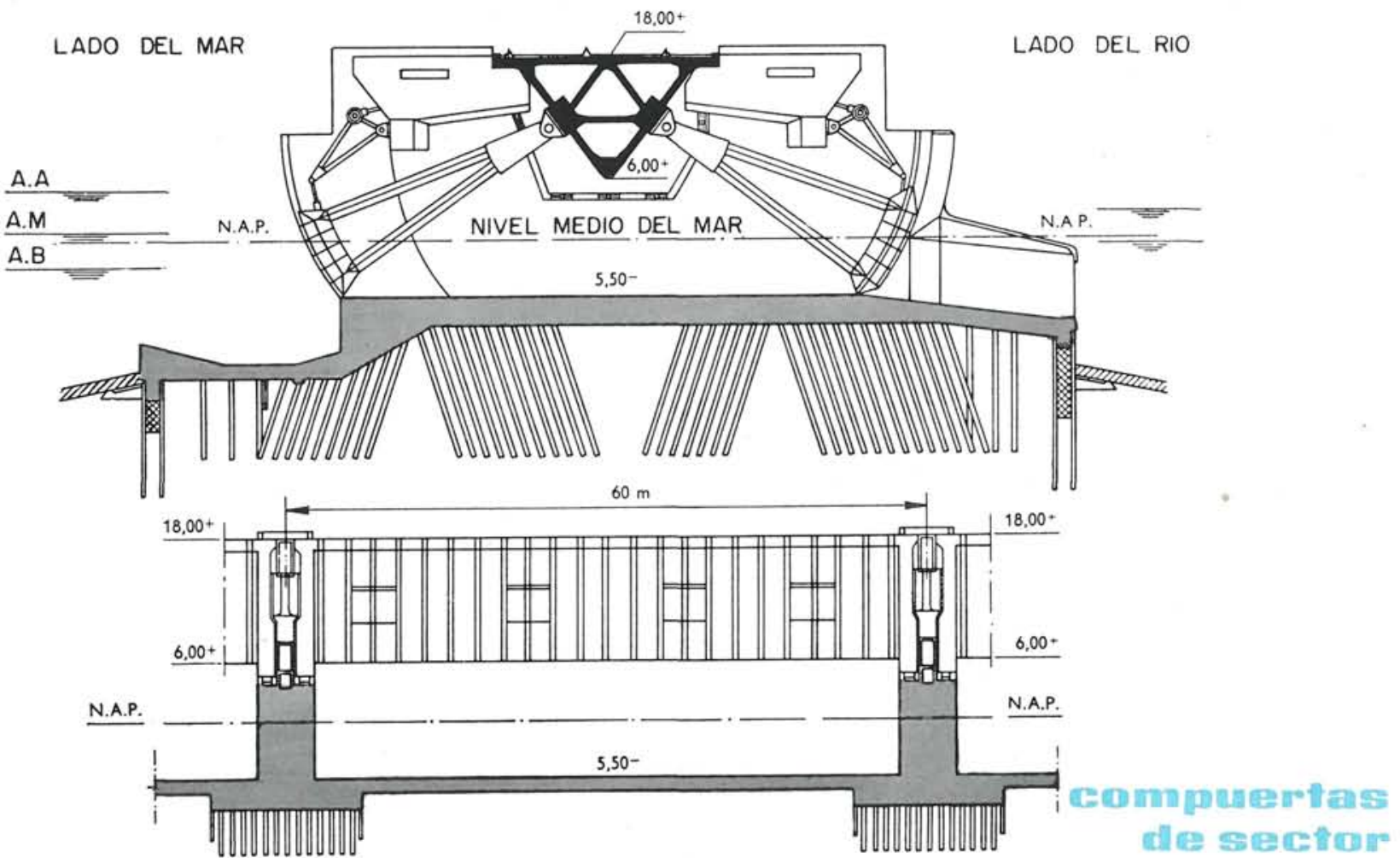




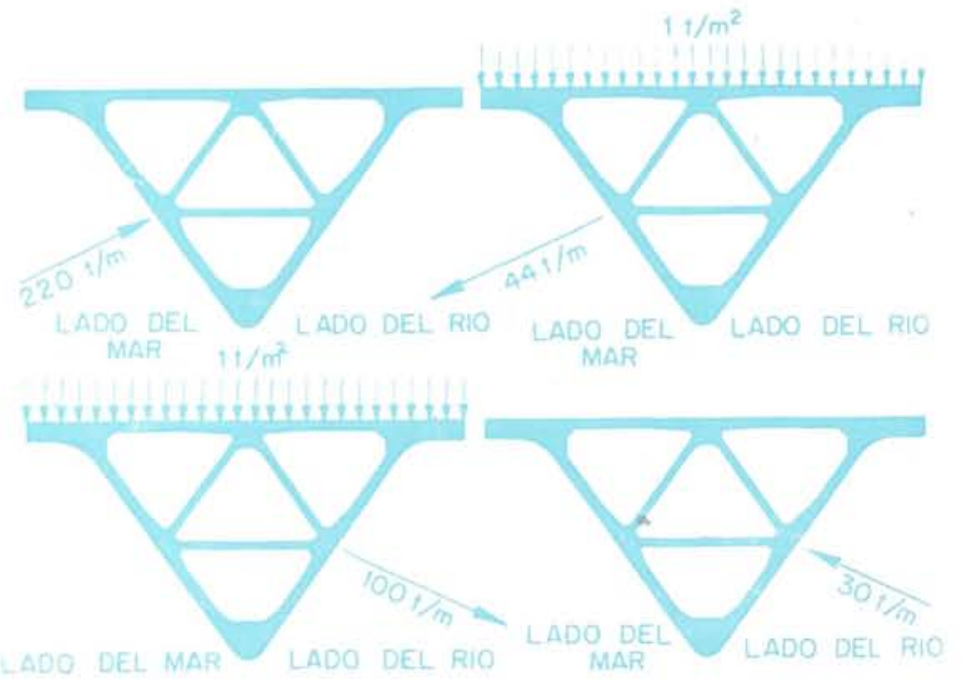

Vigas de tablero.
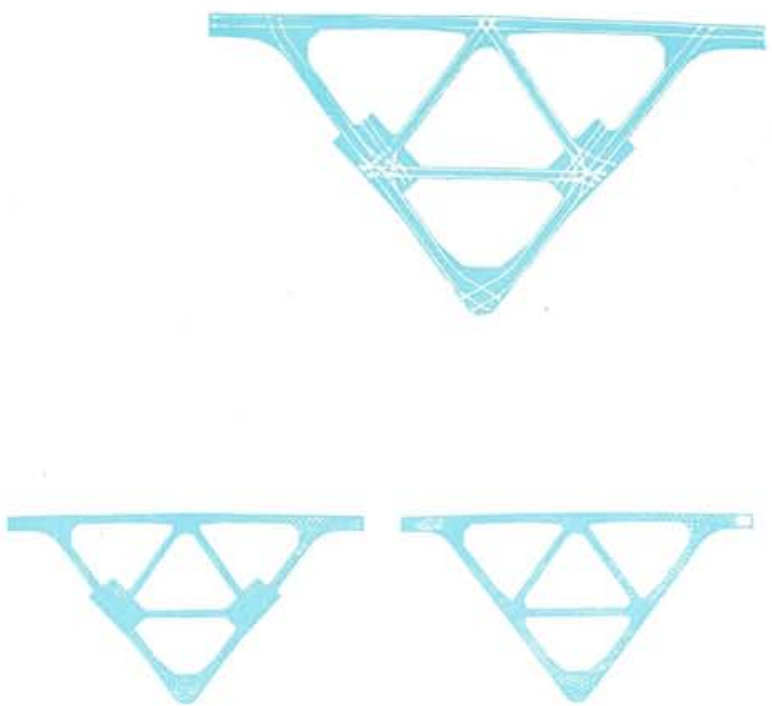

Armaduras longitudinal y transversal de las vigas de tablero

están constituidos por un cajón triangular de $12 \mathrm{~m}$ de altura con paredes de $60 \mathrm{~cm}$ de grueso subdividido en cuatro triángulos equiláteros mediante tabiques de $50 \mathrm{~cm}$, que enlazan los puntos medios del triángulo externo. La base superior se prolonga por ambos lados en voladizo para completar los 22,40 $\mathrm{m}$ del ancho de la plataforma, reforzándose los nudos de la retícula triangular mediante acartelamientos rectos. Las extremidades se rigidizan por dos diafragmas que desbordan lateralmente para dar una base trapecial de apoyo estable.

El pretensado longitudinal se obtiene por 193 cables parabólicos de 51 alambres ae 6 mm cada uno, tipo BBRV, dando una fuerza eficaz de 136,8 t. Los cambios de dirección se verificaban en las juntas, siendo los conductos rectos a lo largo de una rebanada. El pretensado transversal se consigue con cables Freyssinet de 12 alambres de $7 \mathrm{~mm}$ con 43,2 t por cable, dispuestos rectos en ambas caras de los diafragmas con una pequeña incurvación en los anclajes.

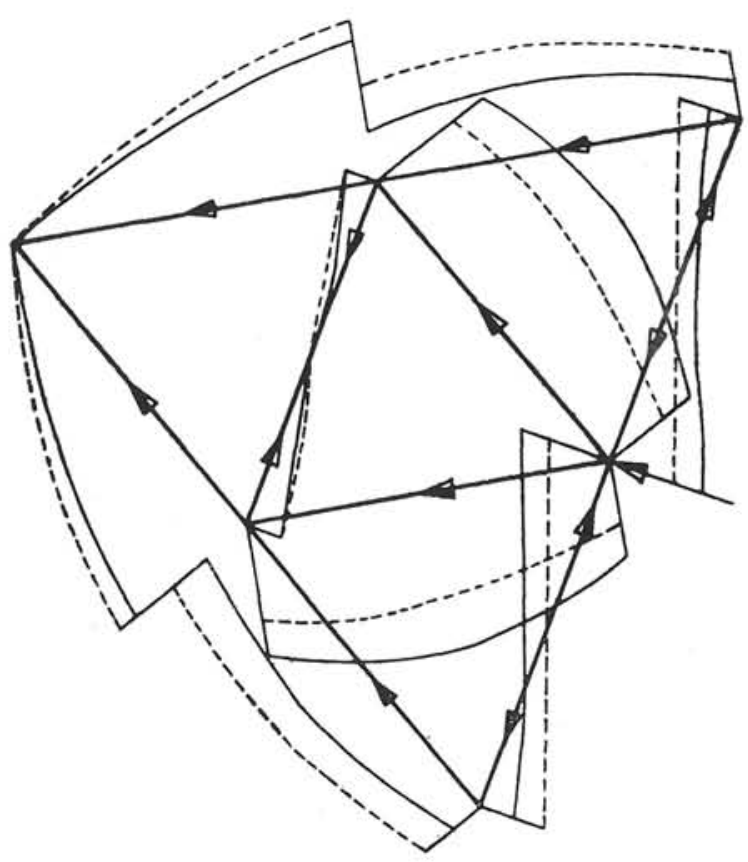

Cuñas de cierre.

Esquema de esfuerzos.

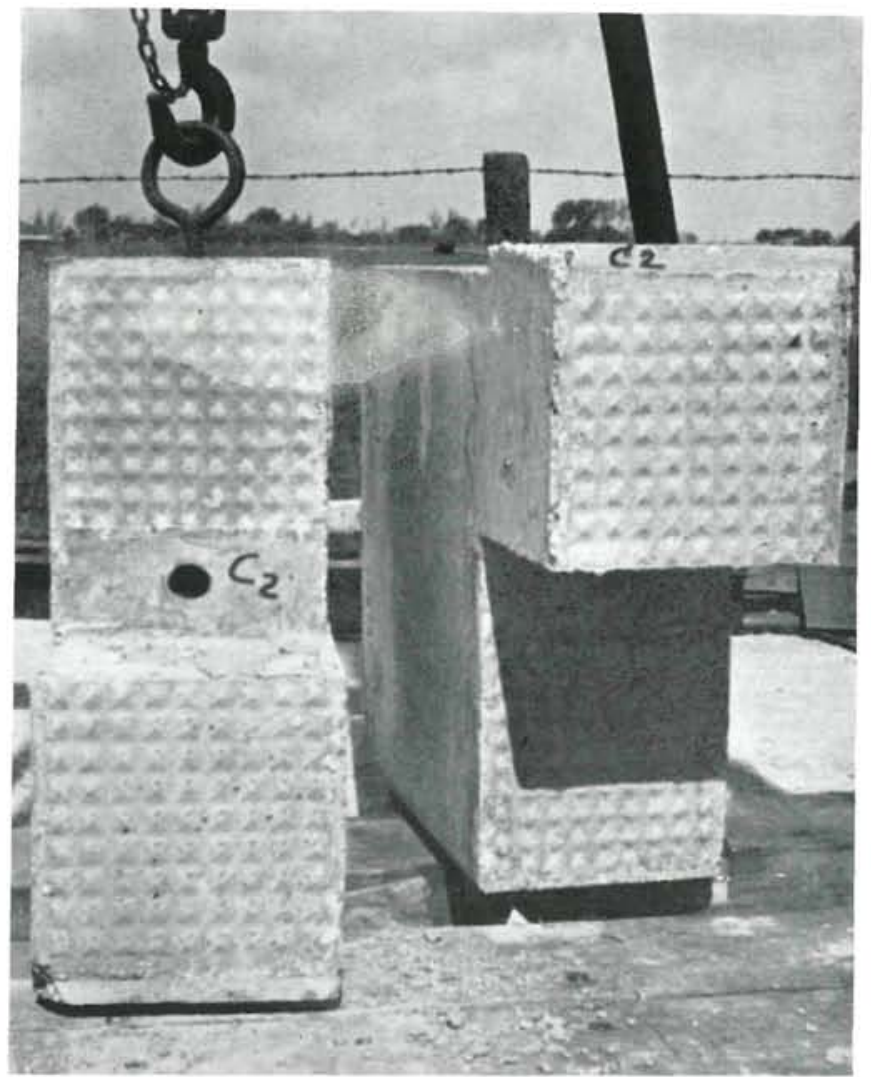



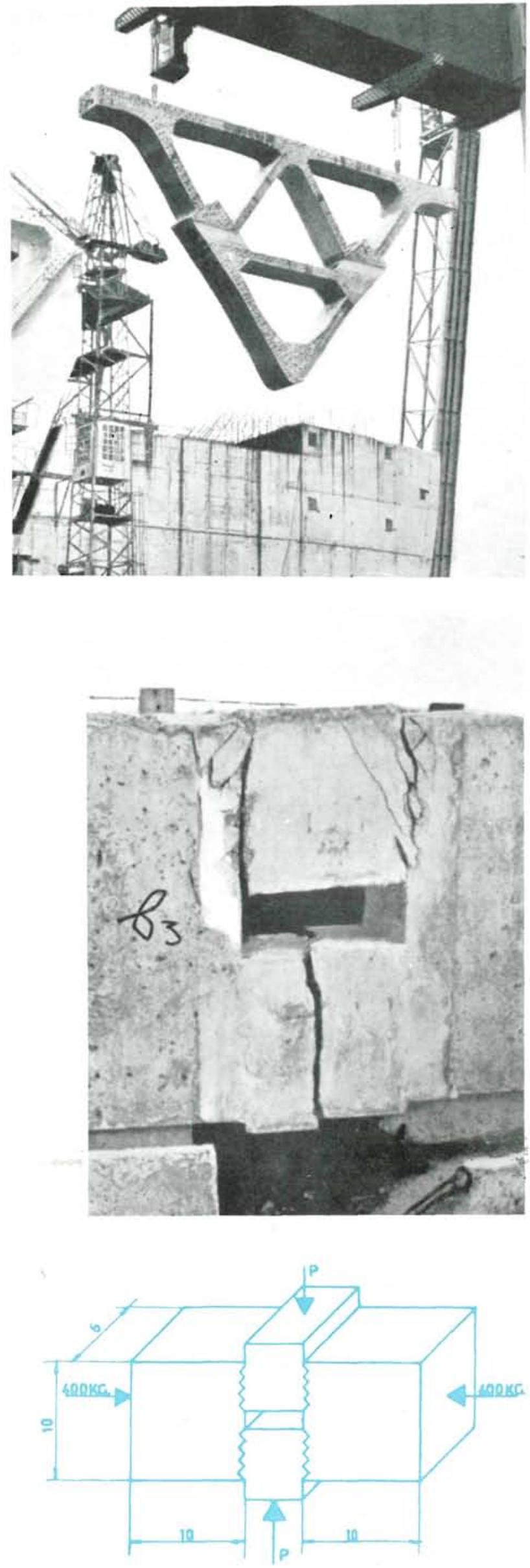

Montaje de un elemento de la viga de tablero.

Ensayo a rotura de una cuña de cierre.

Cuña de cierre.

Teniendo en cuenta las dimensiones de la sección, el pequeño espesor de los diafragmas y la gran cantidad de hormigón que es preciso colocar por viga, se adaptó desde el principio la prefabricación en rebanadas para montarlas en obra sobre andamio y unirlas por el pretensado longitudinal. Se adoptaron 22 rebanadas de $2 \mathrm{~m}$ de longitud y juntas de $50 \mathrm{~cm}$, pesando cada una $250 \mathrm{t}$, siendo distintas las extremas que llevan el diafragma transversal de rigidez y sustentación. Estas rebanadas finales, con las cabezas de anclajes, se moldearon en tres partes y se inontaron directamente sobre las pilas.

En las normas de cálculo se tuvo muy presente el peligro de la corrosión, no aceptándose tensiones principales de tracción para cargas de servicio y, además, que para un incremento del 30 por 100 en las acciones básicas las tensiones principales de tracción no pasaran de $10 \mathrm{~kg} / \mathrm{cm}^{2}$. El coeficiente de seguridad a rotura se fijó en 2,2 .

El primer problema que se presentó en el cálculo fue la validez de la teoría de las piezas prismáticas en esta estructura, en donde las dimensiones externas de la sección son tan importantes relativamente a la luz (12 contra 60), los espesores de los tabiques, por el contrario $(50$ y $60 \mathrm{~cm})$, muy pequeños respecto a las dimensiones, y la trabazón del conjunto de placas difiere mucho de la sección concentrada, clásica de las piezas prismáticas.

Para asegurarse en esta cuestión se construyó un modelo en acero, a escala 1:100, que correspondía a una concepción primitiva con sólo tabiques internos en las zonas de transmisión de los empujes. Los resultados experimentales diferían en un 10 por 100 de los teóricos, considerando la validez de la teoría de piezas prismáticas y otro tanto de los resultados obtenidos al calcular la estructura como placa plegada. Posteriormente se modificó la concepción primitiva, extendiendo los tabiques internos a toda la longitud del dintel, y entonces la aplicabilidad es mucho más admisible, como demostró el ensayo definitivo en modelo de hormigón armado a escala 1:15.

El segundo problema que se presentó es la aplicabilidad de la teoría en las zonas donde se aplican las acciones concentradas, bien de transmisión de empujes, o bien de transmisión de reacciones de sustentación. Aplicando en estas zonas la teoría de la viga o la de placa, los resultados del cálculo diferian bastante. Las tensiones tangenciales correspondientes al reparto de las cargas concentradas, llegan a ser del orden de $35 \mathrm{~kg} / \mathrm{cm}^{2}$, pero teniendo en cuenta el pretensado doble de $55 \mathrm{~kg} / \mathrm{cm}^{2}$, en dirección longitudinal y de $26 \mathrm{~kg} / \mathrm{cm}^{2}$, en dirección transversal en todos los diafragmas, las tensiones principales resultan siempre de compresión para las cargas de servicio.

En la hipótesis de rotura supuesta, la cabeza de compresión coincide con el diafragma exterior del lado del mar, cuyo espesor es relativamente pequeño, respecto de la altura, por lo cual se temió que la rotura quedara condicionada por la resistencia a cortadura a lo largo de las juntas entre el hormigón prefabricado y el ejecutado «in situ». Esto determinó un amplio programa de experimentación directa para asegurarse de la resistencia y, además, comprobar distintas soluciones de acabado de las superficies prefabricadas y de la consistencia del hormigón de relleno entre las piezas. Se probaron superficies con ondulaciones sinusoidales, con redientes en forma piramidal de diferentes relieves, con entrantes en punta de diamante con superficie moldeada, poniendo metal deployé de 1,5 a $2,5 \mathrm{~cm}$ y superficies dentales en dirección perpendicular a la cortadura. 

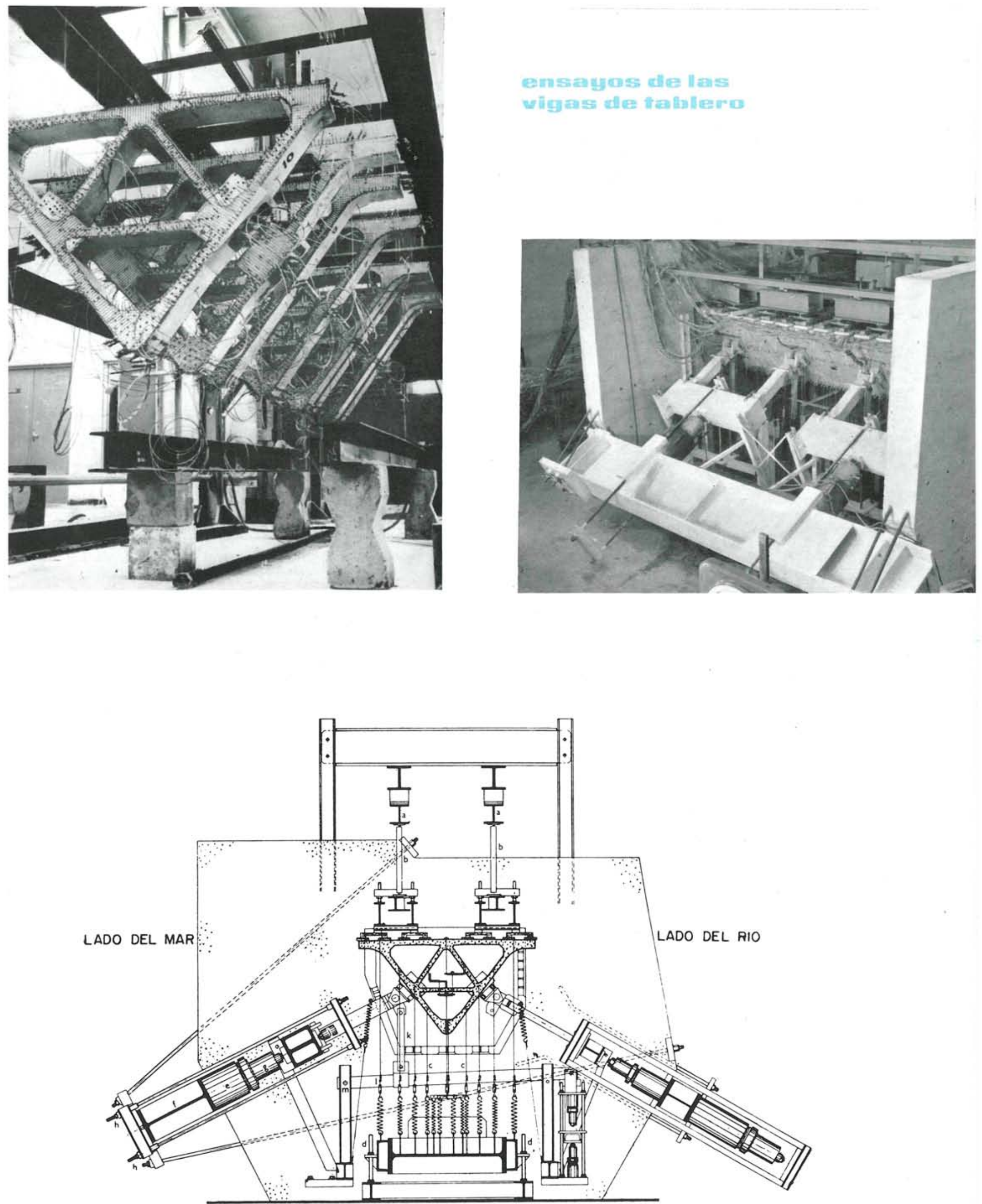

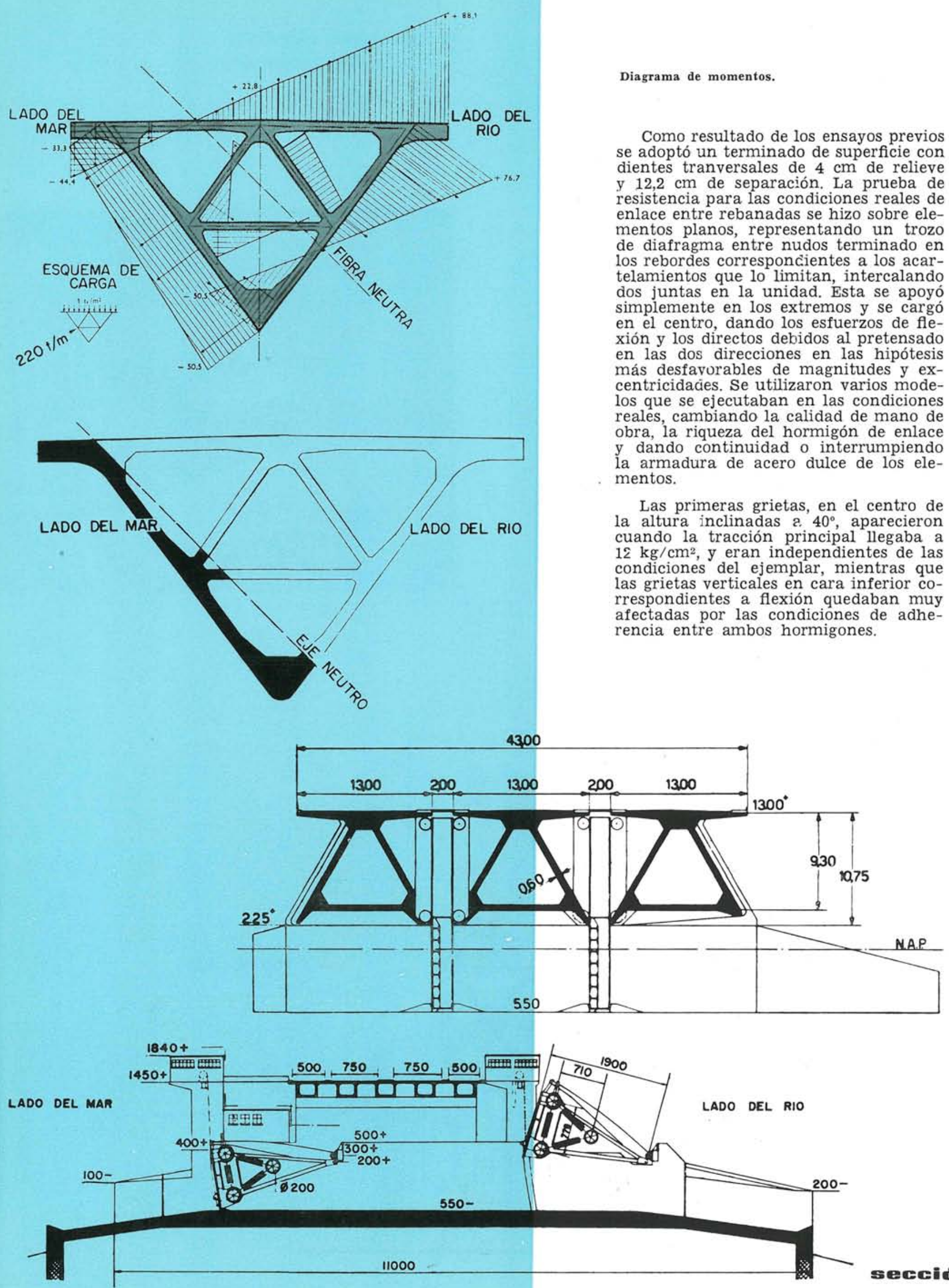

seección 


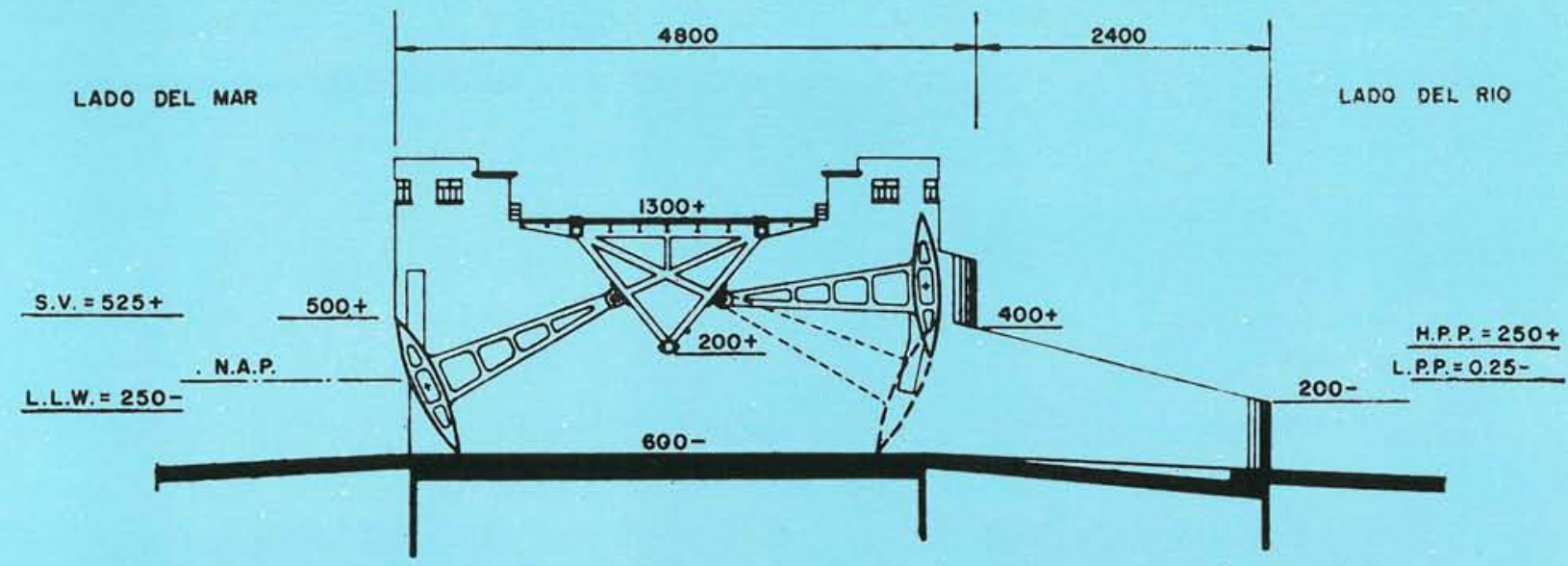

VARIANTE 1
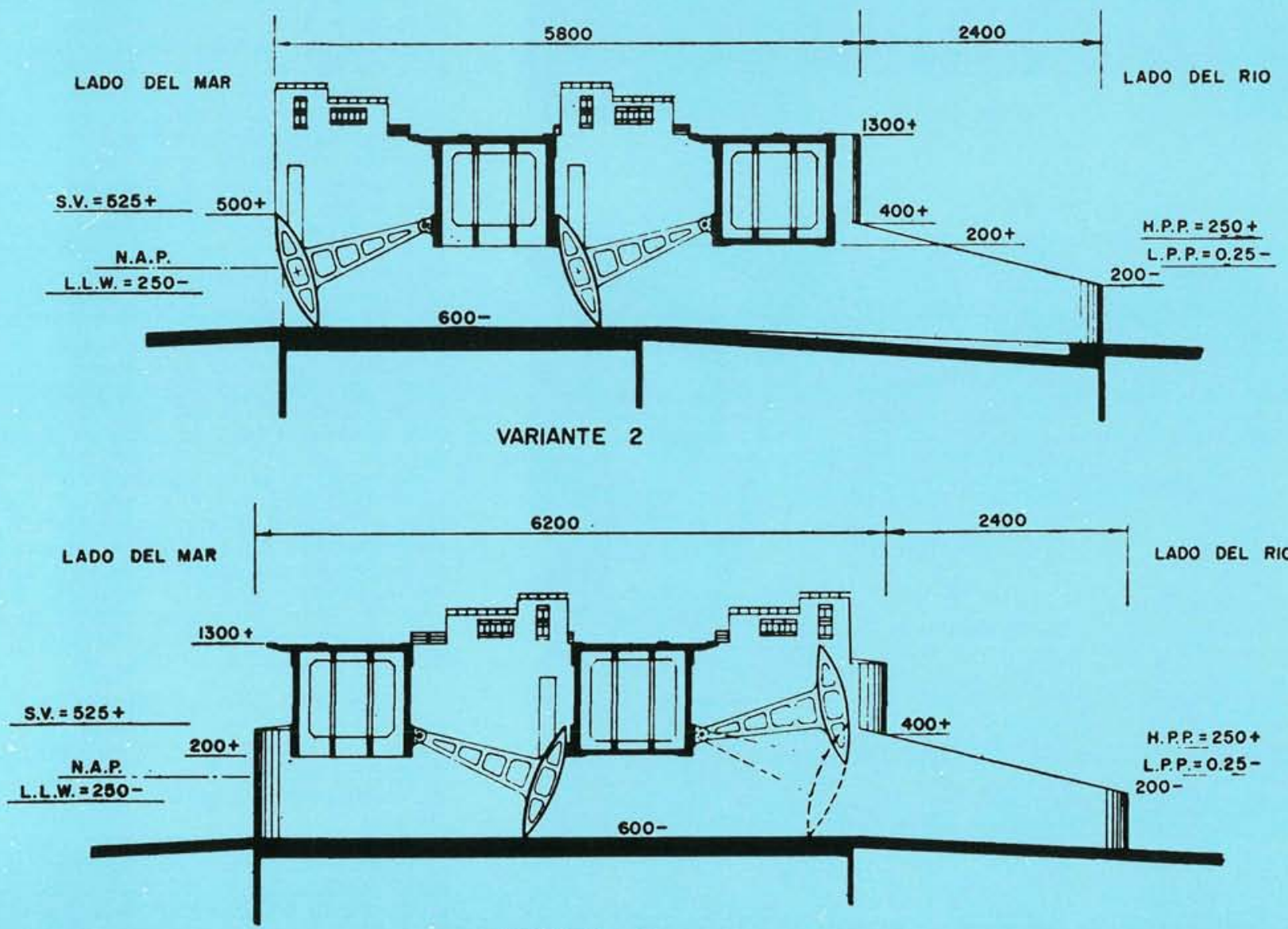

VARIANTE 3

Variantes de compuerta

Al aumentar la carga, las grietas a $40^{\circ}$ se hacían más anchas y numerosas, y la rotura se producía por un aplastamiento en cabeza de compresión con expulsión de una cuña de hormigón y, simultáneamente, el corte del hormigón en la junta o en sus proximidades.

Otro problema que se estudió con todo detenimiento fue la acción correspondiente a diferencias de temperatura entre las superficies del hormigón, ya que las caras laterales por orientación quedan en sombra mientras que la cara superior ha de recibir el soleamiento directo, lo cual puede producir en pocas horas una diferencia de $25^{\circ} \mathrm{C}$ entre dichas caras. Para mitigar los efectos se decidió colocar una losa de $18 \mathrm{~cm}$ por encima del tablero, dejando una cámara de aire con la cual las tensiones se reducen a $15 \mathrm{~kg} / \mathrm{cm}^{2}$ en losa superior. 

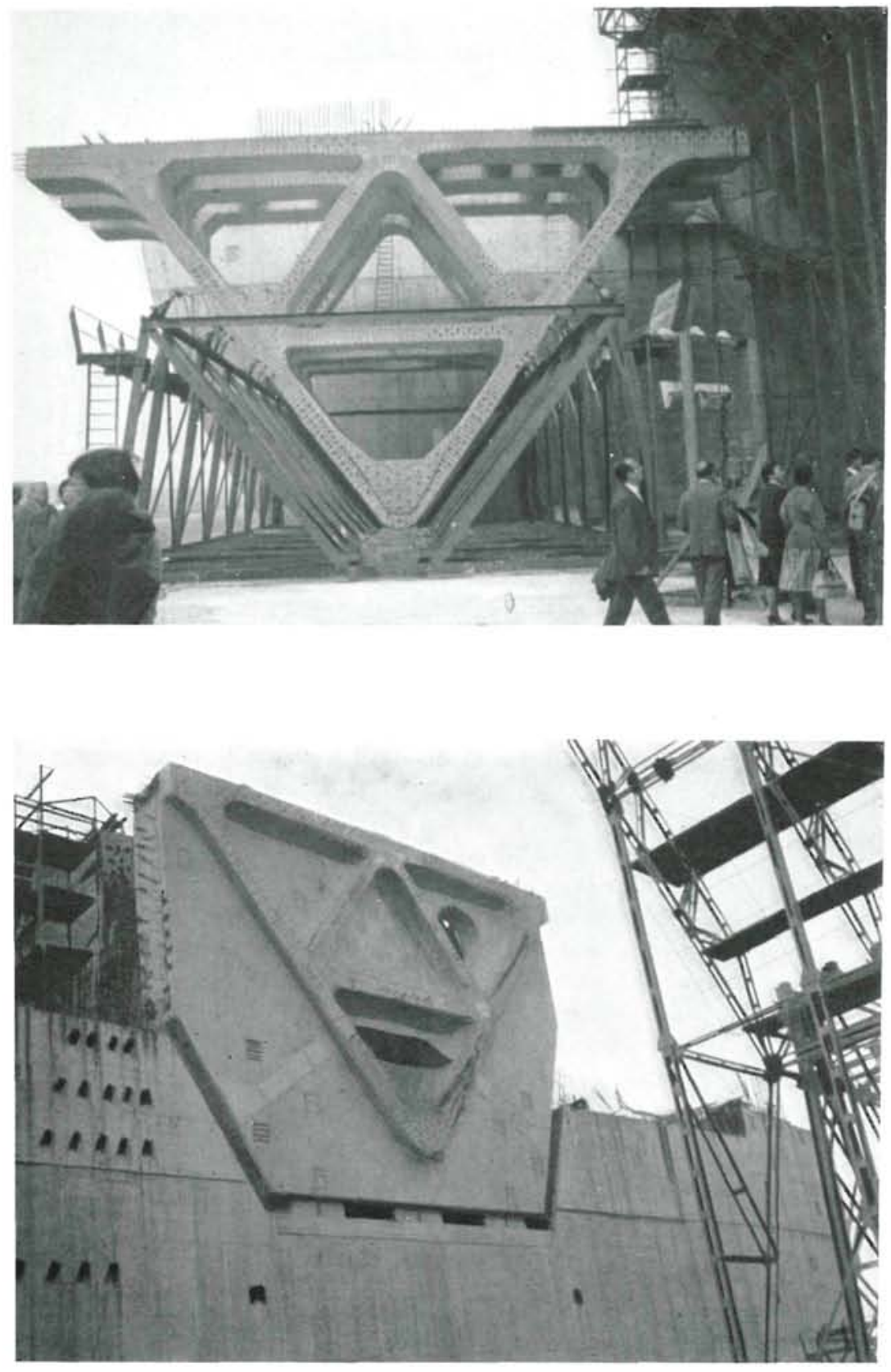

fosers die constructécion

E1 último ensayo se realizó sobre un modelo completo de hormigón, a escala $1 / 15$, construido por rebanadas en condiciones similares a la realidad, sometiéndolo a las acciones normales positivas e, incluso, a un asiento desigual de los extremos que pudiera producir una torsión de la viga al girar las cabezas. Se midieron deformaciones unitarias en superficies internas y externas, con ayuda de 700 extensómetros eléctricos y extensómetros mecánicos, y las flechas horizontales y verticales en gran número de puntos. Se hicieron todas las combinaciones de acciones en servicio y con un incremento del 30 por 100 , y, finalmente, se incrementó la acción correspondiente al empuje del lado del mar hasta 3,9 veces, teniendo que dar fin a los ensayos porque los anillos de medición de carga no tenían resistencia para seguir aumentando. Se obtuvo un buen acuerdo entre los resultados de la experiencia y los de cálculo en hipótesis de pieza prismática.

La primera grieta apareció en la junta central para un valor cero de la tensión en cabeza inferior y, en cambio, el agrietamiento de las juntas adyacentes correspondió a fracciones de 10 a $20 \mathrm{ki}-$ logramos $/ \mathrm{cm}^{2}$. Hasta la máxima carga aplicada todas las grietas fueron de flexión, no apareciendo ninguna correspondiente a cortadura.

Como final copio el párrafo con que el Departamento de Información del Ministerio van Verkeer en Waterstaat termina un pequeño folleto, editado para dar a conocer este plan:

"En la ejecución del Plan Delta se invertirán veinticinco años de trabajo de difícil realización, y Holanda volcará en ella todo su ingenio científico y técnico, basándose en la experiencia adquirida en tantas otras obras de ingeniería hidráulica. Y así, pues, cuando los ingenieros hidráulicos holandeses hayan llevado a cabo su cometido, entregarán las herramientas a los planólogos para que desarrollen el territorio del Delta de la forma más armoniosa posible. A la vez no se perderá de vista el hecho de que este territorio ha venido a situarse muy cerca del corazón de Holanda, junto a las grandes urbes, al lado de los grandes puertos y de las industrias de talla. En estos momentos se están elaborando planes con objeto de dar al territorio del Delta un lugar digno dentro del total de las actividades económicas que Holanda está predestinada a desempeñar por su situación geográfica y en el marco de la comunidad económica europea."

La documentación de este puente se ha tomado del informe del Comité de la STUVO, que fue posteriormente presen. tado al Congreso de la FIP en Roma (1962), y de las revistas: "De Ingenieur" (mayo 1961) "Cement" (mayo 1962) y de la visita realizada a la obra (agosto 1961), con motivo del Symposium de la I.A.S.S., en Delft, sobre "Métodos aproxima. dos de cálculo de láminas». 


\section{Le plaum Delter, Hollumale} La Hollande manquant de recours naturels de surface, a orienté son développement vers l'industrialisation et les soins
maxima apportés au sol-dont la partie occidentale est d'un niveau inférieur à celui de la mer et est habitée par le $65 \%$
de sa population-pour l'exploitation agricole.

A son origine, la côte était découpée en des iles, en baỉes et en promontoires que la main de 1'homme a transformés, d'sbord, en des lacs-polders - et, plus tard, en des terres fertiles. Ces ouvrages maritimes protègent les terres arides à l'aide de digues qui exigent un entretien et une surveillance extrềe, car les inondations violentes ne sont pas rares.

Un des grands problèmes créés par cette situation est celui du complexe approvisionnement en eau, les voies de communioation et l'écoulement des cours d'eau vers la mer dans la zone du delta, c'est-à-dire le sud-ouest du pays, pour la protection de laquelle, une Commission nationale a été constituée.

Après de sérieuses études, on arriva à la conclusion que la meilleure défense contre las attaques de la mer consiste à en fermer les bras qui pénètrent dans le continent. L'ensemble d'aménagements hydrauliques représente le plan
tions et de défenses, pour le développement et exécution duquel a été prévue une période de vingt-cinq années.

Le projet général est très ambitieux et comprend des ouvrages, non seulement maritimes, mais aussi routiers et structuraux, dans lesquels les ouvrages de maçonnerie sont variés et de nature différente. Cet article décrit, dans ses grandes lignes, les thèmes prineipaux objet des onze alinéas, en quoi a été divisé le projet général d'exécution et complète les des. criptions par des données additionnelles concernant les travaux déjà commencés et les méthodes constructives qui y ont été applíquées. De ces derniers travaux le pont Nabla, situé sur le delta, mérite une attention spéciale. Ce pont est en béton précontraint et se compose de dix-sept tronçons de $60 \mathrm{~m}$ de portée chacun. Cette énorme structure, en plus de sa longueur et de servir d'appui à une chaussée de $22,80 \mathrm{~m}$ de largeur, est soumise aux terribles poussées des eaux de mer d'un côté et de lautre des eaux douces, du bras de Haringviet, estuaire commun du Rhin et de la Meuse, Les piles qui supportent le tablier, avee des articulations de caoutchouc interposées, sont chargées de transmettre les pous. sées des eaux au terrain.

La précontrainte est formée par 193 câbles, de tracés paraboliques, tressés au moyen de 51 fils de 6 mm de diamètre chacun qui sont soumis à un effort de 136,8 t. La précontrainte transversale a été réalisée à l'aide de câbles type Freyssinet de 12 fils, de $7 \mathrm{~mm}$ de diamètre, travaillant à 43,2 t par câble et de tracé rectiligne.

Les poutres du tablier sont du type préfabriqué, ce qui a permis de gagner de gros avantages. Une attention toute particulière a été prêtée à la currosion pour l'étude des câbles.

Dans le calcul résistant des poutres, une attention spéciale a été attachée à la théorie de pièces prismatiques et à leur possible validité dans ce cas particulier. Pour plus de sécurité on prépara un modèle réduit. Les résultats obtenus des essais que pliée, l'analyse théorique n'a pas différé de plus du $10 \%$ des résultats expérimentaux.

Le second problème étaít la possibilité d'appliquer la théorie de transmission de poussées on de réactions dans les zones de forces concentrées, où les théories de poutre ou de plaque de différence relative étaient considérables.

Pour le cas de rupture différentes solutions concernant les surfaces de contact et les extrémités de poutres furent étudiées. Les essais sur modèle ont servi de complément aux prévisions qui avaient été considérées pour les différentes analyses de ces zones et surfaces.

On a étudiế également l'influence différentielle de la température, le soleil donnant d'un côté et l'ombre đe l'autre.

Finalement, on a préparé un modèle réduit đe tout l'ouvrage où l'on a apprécié de petites différences admissibles par rap. port aux prévisions analytiques.

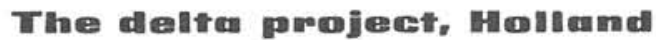

Holland is very poor in land resources. Hence its development has been directed towards intensive industrialization and maximum agricultural exploitation. The western part of the country is below sea level and is occupied by 65 percent of the population.

Originally the coast consisted of a number of islands, estuaries and slight elevations. Man has transformed this coastline, first making a number of artificial lakes, or polders, and then converting these into fertile districts. These projects protect
the soil by means of dykes, which require careful conservation, but even so violent floods are not infrequent.

One of the difficult problems involved in this vast enterprise is the complex system of water supply, lines of communi. cation and flow of the rivers into the sea

After careful study, it was decided that the best defense against the violence of the sea would consist in closing off the inroads of the sea into the continental coastline. The set of hydraulic projects which constitutes this plan for the improvement of the sea defences will take 25 years to fulfil.

The general project is highly ambitious and includes both maritime, road and structural works, in which there is a variety of stonework constructions.

This paper describes, in brief outline, the main contents of the 11 headings into which the general construction project has been subdivided. In addition, this is supplemented with information on the projects which are already initiated and on is situted the procts structure, in addition to its great length, and supporting a $22.8 \mathrm{~ms}$ wide roadway, is subjected to the tremendous forces 
of the sea on one side, and to the thrust of the Haringvliet estuary current on the ether. This estuary is common to the Rhine and Meuse rivers. The bridge will serve as supporting structure for the flood gates which are to control the volume of river water flow, and which will close off the entry of sea water. The piles, will

Prestressing is accomplished by means of 193 cables, running along parabolic curves. Each of the cables is made up of 51 wires, each $6 \mathrm{~mm}$ in diameter, and carry a load of 136.8 tons per cable. Transversal prestressing is by means of Freyssinet cables, each consisting of 12 wires, of $7 \mathrm{~mm}$ diam. each, and carrying a load of 43.2 tons per cable.

The deck beams are prefabricated; this results in significant advantages. The danger of corrosion, which is greatly enhanced owing to the nearness of the sea, was carefully considered when designing the cables.

When calculating the strength of the beams, detailed thought was given to the validity of assuming a bending theory in which plane sections remain plane after deformation. For greater safety a reduced scale model was built. The results yielded by the tests showed that both in the case of assuming a plane section bending theory or in assuming the structure to be a folded slab, the theoretical analysis gave results that differed by less than $10 \%$ from the experimental ones.

Another theoretical problem was to decide on how to consider the transmission of thrusts and reactions at the zones of concentrated forces, where elastic or plastic bending theories were in doubt.

At the extremities of the beams, a number of alternative solutions were investigated regarding the bearing surfaces. Tests on reduced scale models helped to complement the theoretical analyses which had been worked out about these critical zones and surfaces.

The influence of temperature differences was another difficulty, especially in the case where the sun shines on one side of the structure, whilst the opposite side is cold.

Finally, a model of the whole structure was completed, and tests on it showed that there were small discrepancies between the analytical and test results, but these were well within the admissible margins of error.

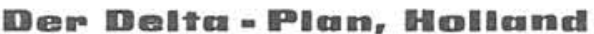

Holland fehlen die natürlichen Oberfiächen, weshalb sich seine Entwicklung auf die Industrialisierung und auf die höchste Bodenpflege für die landwirtschaftliche Ausnützung gerichtet hat. Der westliche Teil des Landes befindet sich unter dem Meeresspiegel, und gerade dort leben $65 \%$ seiner Bevölkerung.

Ursprünglich zeigte die Küste eine von Inseln, Buchten und Vorgebirgen zerschnittene Eigenart, welche die Menschenhand zunächst in Seen (Polder) und später in fruchtbares Land umwandelte. Die Meereswerke schützen das Trockenland Dämme, die eine sorgfältige Erhaltung fordern, und selbst so sind die gewaltigen Uebersc

Eines der grossen Probleme, welche diese Lage schafft, bildet in dem Delta-Gebiet der Komplex der Wasserversorgung, der Verkehrsiinien und der Entwässerung der Flüsse zum Meer hin, das heisst zum Schutze des Südwestens des Landes, wofür eine National-Kommission gebildet wurde.

Nach ernsten Studien gelangte man zu dem Schluss, dass die beste Verteidigung gegen die Meeresbrandung jene sei, die Verbesserungen und Verteidigungen, für deren Entwicklung und Ausführung man eine Periode von 25 Jahren vorgesehen hat.

Der allgemeine Plan ist sehr ehrgeizig und umfasst nicht nur Meeres-sondern auch Strassen-und Bawwerke, bei welchen die Fabrikswerke abwechselnd und von verschiedener Natur sind. In dieser Arbeit werden in grossen Zügen die Hauptthemen beschrieben, welche Gegenstand der 11 Abschnitte sind, in welche das Hauptausführungs-Projekt unterteilt ist; ausserdem werden die Besehreibungen durch zusätzliche Daten bezüglich der bereits begonnenen Arbeiten und den bei ihnen angewandten konstruktiven Methoden vervollständigt. Von diesen letzten Werken verdient die in dem Delta gelegene Brücke von Nabla eine besondere Aufmerksamkeit: sie ist aus Spannbeton und zänlt 17 Abschnitte von $60 \mathrm{~m}$ Weite ein jeder. Diese gewaltige Struktur, abgesehen von ihrer Länge, die zur Stütze für eine Strasse von 22,80 m Breite dient, ist auf einer Seite den furchtbaren Stossen, die das Meereswasser ausübt, und auf der anderen Seite dem Süsswasser des

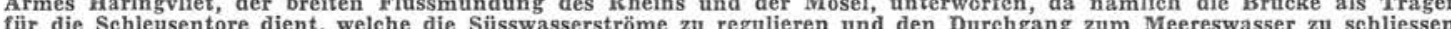

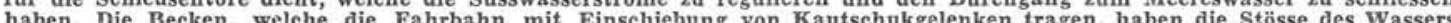
auf die Erde zu übertragen.

Die Vorspannung wird aus 193 Kabeln mit parabolischer Trassierung, ein jedes geflochten aus 51 Drähten von 6 mm Durch. messer, gebildet, die einer Kraft von 136,8 t unterworfen sind. Die Quer-Vorspannung wurde aus Freyssinet-Kabeln mit 12 Drähten von $7 \mathrm{~mm}$ Durchmesser ausgeführt, die 43,2 t je Kabel tragen und eine geradlinige Trassierung zeigen. Die Balken der Fahrbahn sind vorgefertigter Art, womit bemerkenswerte Vorteile erzielt wurden. Beim Studium der Ka bel wurde die Korrosion besonders in Betracht gezogen.

Bei der Widerstandsberechnung der Balken war die Theorie der prismatischen Körper Gegenstand der Beachtung und ihre in diesem besonderen Falle mögliche Gültigkeit. Zur grösseren Sicherheit wurde ein Modell in kleinerem Masstabe be reitet. Die bei den Versuchen erlangten Ergebnisse zeigten, dass sowohl bei der Theorie der prismatischen Körper, als auch bei Annahme einer Struktur mit Faltplatten die theoretische Untersuchung nicht mehr als $10 \%$ von den experimentellen
Ergebnissen verschieden war.

Das zweite Problem bestand in der Möglichkeit, die Theorie der Stoss-oder Reaktionen-Uebertragung auf die Zonen der konzentrierten Kräfte anzuwenden, wobei sich die Balken-oder Plattentheorie mit relativem Unterschied als beachtlich ergab.

Für den Bruchfall wurden verschiedene Lösungen bezüglich der Kontaktflächen und der Balkenenden studiert. Die Versuche am Modell dienten den Voraussichten, welche bei den verschiedenen Untersuchungen an diesen Zonen und Flächen ausaeführt worden waren, zur Ergänzung.

Auch war der unterschiedliche Temperatureinfluss Gegenstand des Studiums, indem man die Sonne auf die eine Seite scheinen liess, während die andere im Schatten verblieb.

Schliesslich wurde ein verkleinertes Modell des Gesamtwerkes hergestellt und schätzte an ihm die kleinen und annehmbaren Unterschiede mit Beziehung auf die analytischen Voraussichten. 